\title{
Zebrafish Larvae Carrying a Splice Variant Mutation in cacna1d: A New Model for Schizophrenia-Like Behaviours?
}

\author{
Nancy Saana Banono ${ }^{1}$ (D) Kinga Gawel $^{1,2}$ (D) Linus De Witte $^{3} \cdot$ Camila V. Esguerra $^{1,4}$ (D)
}

Received: 6 July 2020 / Accepted: 2 October 2020 / Published online: 14 October 2020

(C) The Author(s) 2020

\begin{abstract}
Persons with certain single nucleotide polymorphisms (SNPs) in the CACNA1D gene (encoding voltage-gated calcium channel subunit alpha 1-D) have increased risk of developing neuropsychiatric disorders such as bipolar, schizophrenia and autism. The molecular consequences of SNPs on gene expression and protein function are not well understood. Thus, the use of animal models to determine genotype-phenotype correlations is critical to understanding disease pathogenesis. Here, we describe the behavioural changes in larval zebrafish carrying an essential splice site mutation (sa17298) in cacnalda. Heterozygous mutation resulted in 50\% reduction of splice variants 201 and 202 (haploinsufficiency), while homozygosity increased transcript levels of variant 201 above wild type (WT; gain-of-function, GOF). Due to low homozygote viability, we focused primarily on performing the phenotypic analysis on heterozygotes. Indeed, cacnalda ${ }^{\text {sa17298/WT }}$ larvae displayed hyperlocomotion-a behaviour characterised in zebrafish as a surrogate phenotype for epilepsy, anxiety or psychosis-like behaviour. Follow-up tests ruled out anxiety or seizures, however, as neither thigmotaxis defects nor epileptiform-like discharges in larval brains were observed. We therefore focused on testing for potential "psychosis-like" behaviour by assaying cacnalda ${ }^{\text {sa17298/WT }}$ larval locomotor activity under constant light, during light-dark transition and in startle response to dark flashes. Furthermore, exposure of larvae to the antipsychotics, risperidone and haloperidol reversed cacnalda-induced hyperactivity to WT levels while valproate decreased but did not reverse hyperactivity. Together, these findings demonstrate that cacnalda haploinsufficiency induces behaviours in larval zebrafish analogous to those observed in rodent models of psychosis. Future studies on homozygous mutants will determine how cacnald GOF alters behaviour in this context.
\end{abstract}

Keywords Zebrafish $\cdot C A C N A 1 D \cdot$ Neurobehaviour $\cdot$ Neuropsychiatric disorders $\cdot$ Schizophrenia $\cdot$ Psychosis

Electronic supplementary material The online version of this article (https://doi.org/10.1007/s12035-020-02160-5) contains supplementary material, which is available to authorized users.

Camila V. Esguerra

c.v.esguerra@ncmm.uio.no

Linus De Witte

https://orcid.org/0000-0002-2374-637X

1 Chemical Neuroscience Group, Centre for Molecular Medicine Norway (NCMM), Faculty of Medicine, University of Oslo, Gaustadalléen 21, Forskningsparken, 0349 Oslo, Norway

2 Department of Experimental and Clinical Pharmacology, Medical University of Lublin, Jaczewskiego Str. 8b, 20-090 Lublin, Poland

3 Pharmaceutical and Biological Sciences, AP Hogeschool Antwerpen, Antwerp, Belgium

4 School of Pharmacy, Faculty of Mathematics and Natural Sciences, University of Oslo, Sem Sælandsvei 24, 0371 Oslo, Norway

\section{Introduction}

Schizophrenia (SCZ) is a highly heritable and polygenic neuropsychiatric disorder. The high prevalence of SCZ worldwide has made it a burgeoning public health concern. Genome-wide association studies (GWAS) have led to the initial identification of small nucleotide polymorphisms (SNPs) in about 108 risk loci linked to SCZ [1]. The majority of SNPs implicated in SCZ and other psychiatric disorders are located in noncoding (intergenic and intronic) regions of the genome [2]. To date, the functional significance of these noncoding variants remains unclear, thus obviating the need for establishment and validation of genetic animal models to elucidate underlying disease mechanisms associated with SCZrisk genes. Nevertheless, SNPs in the intronic regions of genes are thought to result in changes in gene expression levels by altering splicing (via splice donor or acceptor sites) and transcription (via disruption of gene regulatory elements such as 
transcription factors, promoters, enhancers and/or suppressors) [3, 4]. For example, there is evidence that rs 100637 (a SCZ-associated SNP, located in intron 3 of the CACNAIC gene) is associated with major depressive disorder (MDD), $\mathrm{SCZ}$ and attention deficit hyperactivity disorder, leads to changes in CACNA1C expression in both human carriers [5, 6] and induced human neurons [7]. In humans, broader phenotypes are present such as deficits in prepulse inhibition (PPI), latent inhibition and sleep disturbance in some SNP carriers, mimicking a broad spectrum of neuropsychiatric disorders $[2,8]$.

CACNA1D encodes the $\alpha 1$ subunit of the $\mathrm{CaV}_{1.3}$ voltagegated L-type isoform. In the central nervous system (CNS) of humans, the $\mathrm{CaV}_{1.3}$ isoform is expressed in neuroendocrine cells, cerebral cortex, habenula, hippocampus, thalamus and basal ganglia, where it plays essential roles in consolidation of fear memory, drug-seeking behaviours and fine tuning of various elements of neuronal plasticity [9-12]. Mutations in CACNA1D have been implicated in neurodevelopmental and neuropsychiatric diseases [13-15]. For instance, persons with SNPs in CACNA1D have increased risk of developing bipolar disorder (BP), attention deficit hyperactivity disorder, SCZ, autism spectrum disorder (ASD) or MDD [1, 13, 16-21]. In one study, two single nucleotide variants in $C A C N A 1 D$ were found in separate cohorts of bipolar patients [22]. Although a study in the Han Chinese population did not find an association of CACNA1D with SCZ [23], other subsequent studies did identify such an association $[8,21]$. Furthermore, wholeexome sequencing revealed variants in the CACNA1D coding region to be linked to $\mathrm{ASD}$, depression, anxiety, fear and seizures $[17,18]$.

Homozygous $\mathrm{CaV}_{1.3}$ knockout mice are deaf and have impaired cardiac function [24], display antidepressant-like phenotypes [25] and have impaired consolidation of fear in the Pavlovian test [26]. In zebrafish (Danio rerio), cacnald is duplicated into cacnalda and cacnaldb, which encode $\mathrm{CaV}_{1.3 \mathrm{a}}$ and $\mathrm{CaV}_{1.3 \mathrm{~b}}$ respectively [27]. The amino acid sequence of zebrafish Cacnalda and Cacnaldb is $77 \%$ and $33 \%$ homologous to human CACNA1D respectively [28, 29]. Previous zebrafish studies have focused primarily on characterising the role of cacnald in auditory and vestibular function [27, 30-32]. Homozygous cacnalda nonsense mutants display a classical auditory-vestibular phenotype reminiscent of "circler mutants" (i.e. circular swimming due to impaired balance) $[27,33,34]$.

Interestingly, the essential splice site mutation described in this study was found to mimic both gene haploinsufficiency in the heterozygous state and gain-of-function (GOF) in the homozygous state. As homozygous mutant survival was low (i.e. very small sample size), we focused the majority of our analysis on heterozygotes, thus investigating the effects of cacnalda haploinsufficiency on larval zebrafish behaviour and electroencephalography (EEG) patterns. We profiled for anxiety-, seizure- or psychosis-like behaviours, by performing the following assays: PPI response, locomotor activity (constant light), light-dark transition test, thigmotaxis and startle response to dark flashes. We also tested the neuromodulatory activity of risperidone (RISP), an atypical antipsychotic drug [35]; haloperidol (HALO), a dopamine antagonist used as a typical antipsychotic drug [36]; and valproic acid (VPA), an anti-seizure drug and mood stabiliser [37, 38], to determine whether cacnald mutant larvae would respond in a similar manner as SCZ, BP and/or epilepsy patients/animal models. Finally, EEG recordings were performed to establish whether the hyperlocomotion observed at earlier developmental time points resulted from epileptiform-like brain activity.

\section{Materials and Methods}

\section{Ethical Considerations}

Approval by the Norwegian Food Safety Authority via its experimental animal administration's supervisory and application system (FOTS-ID 15469 and 23935) was obtained prior to animal experimentation. Also, compliance with the National Institute of Health Guidelines for the Care and Use of Laboratory Animals and the European Community Council Directive of November 2010 for Care and Use of Laboratory Animals (Directive 2010/63/EU), as well as the ARRIVE guidelines, were adhered to during all experiments.

\section{Zebrafish Strains and Husbandry}

The sa17298 mutant line was generated by N-ethyl-Nnitrosourea (ENU) mutagenesis within the Zebrafish Mutation Project (Sanger, UK). The line carries a point mutation in cacnalda, which spans an essential splice site [for details see: [39]]. Fertilised sa17298 embryos were obtained from the Zebrafish International Resource Center (Eugene, Oregon, USA) and raised to adulthood, genotyped and the heterozygous animals outcrossed to $\mathrm{AB}$ wild-type (WT) zebrafish for three generations. Animals were raised under controlled conditions described by [40], in a 14-/10-h light/dark cycle at $28.5^{\circ} \mathrm{C}$.

Fertilised eggs from natural spawning of adult fish lines were collected, transferred to petri dishes (density $N=50-70)$, filled with embryo medium ( $17 \mathrm{mM} \mathrm{NaCl}$, $2 \mathrm{mM} \mathrm{KCl}, 1.8 \mathrm{mM} \mathrm{Ca}(\mathrm{NO} 3), 2,0.12 \mathrm{mM} \mathrm{MgSO} 4$, $1.5 \mathrm{mM}$ HEPES buffer $\mathrm{pH} 7.1-7.3$ and $0.6 \mu \mathrm{M}$ methylene blue). These petri dishes were stored in an incubator with a 14/-10-h light/dark cycle at $28.5^{\circ} \mathrm{C}$. The medium was refreshed daily until larvae reached 7-day post-fertilisation (dpf). 


\section{Genotyping}

Adult fin clip tissue or whole larvae were snap frozen in liquid nitrogen. DNA from fin clip tissue or larval sample was extracted using PCR extraction buffer (10 mM Tris ( $\mathrm{pH} 8.0)$, 2 mM EDTA, $0.2 \%$ Triton $\mathrm{X}-100$ ) and proteinase $\mathrm{K}$ $(200 \mu \mathrm{g} / \mathrm{ml})$. DNA was amplified using DreamTaq DNA polymerase (EP0702, Thermofischer) according to the manufacturer's instructions in a $20 \mu \mathrm{L}$ final volume. The forward primer: 5' TGTGCTGGTGTTGTGTGTG 3' and reverse primer: 5' TCAAGCCAGGAAGTACTGAAG 3' were used with the following cycling conditions: Step 1: Initial denaturation $95{ }^{\circ} \mathrm{C}, 1 \mathrm{~min}$; Step 2: Denaturation $95{ }^{\circ} \mathrm{C}, 30 \mathrm{~s}$; Step 3: Annealing temperature $59{ }^{\circ} \mathrm{C}, 30 \mathrm{~s}$; Step 4: Extension $72{ }^{\circ} \mathrm{C}$, $1 \mathrm{~min}$; Step 5: Repeat steps 2-4, $34 \times$; Step 6: Final extension $72{ }^{\circ} \mathrm{C}, 1 \mathrm{~min}$. This resulted in a 196 base pair (bp) amplicon. The PCR product was digested using the restriction enzyme, BstEII (R0162M, New England BioLabs). The bands were visualised using 2\% agarose gel electrophoresis and Sybr Safe (S33102, Thermofischer) as the DNA intercalating agent. Observers conducting behavioural tests were blind to the genotype of the larvae. Hence, larvae were genotyped after each experiment.

\section{Morphological Assessment}

Larvae were photographed using a Leica M205 FA stereomicroscope and assembled using Adobe Photoshop 2020. All pictures were taken at $5 \mathrm{dpf}$ at the same resolution for comparison.

\section{Drugs}

The following drugs were used: $5 \mu \mathrm{M}$ RISP, $50 \mu \mathrm{M}$ HALO and $100 \mu \mathrm{M}$ VPA. All drugs were dissolved in DMSO at a final concentration of $0.5 \% \mathrm{v} / \mathrm{v}$ DMSO for the HALO and VPA groups but $0.1 \% \mathrm{v} / \mathrm{v}$ DMSO for the RISP-treated group. The appropriate vehicle controls were prepared by dissolving DMSO in zebrafish E3 medium. DMSO and HALO were purchased from Sigma-Aldrich, RISP from TOCRIS and VPA from Sanofi Aventis. The drug concentrations used were selected based on previously published studies [35, 36, 41].

\section{Behavioural Tests and Material}

Larvae were transferred to the behavioural analysis room at least $1 \mathrm{~h}$ prior to experimentation to allow animals to acclimate. Single larvae were gently transferred from the petri dishes to individual wells of a 24 -well plate (diameter $16.2 \mathrm{~mm}$ ) except when stated otherwise. Automated videotracking of larval behaviour was carried out using the ZebraBox hardware and ZebraLab software (Viewpoint, Lyon, France). Light-dark test and thigmotaxis measurement were carried out using the same larvae by simply defining the inner and outer regions of each well of the tracking plate (the inner zone was of diameter $8 \mathrm{~mm}$ while the distance from the inner zone relative to the outer zone was $4 \mathrm{~mm}$ ). A different set of larvae were used for the startle response test. Except for the startle response to dark flashes test, all other experiments were replicated two or three times and the results pooled together.

\section{Locomotor Activity and Thigmotaxis}

Larvae were allowed to acclimate to the test chamber (ZebraBox) for $15 \mathrm{~min}$ in the dark, followed by $10 \mathrm{~min}$ of tracking in either $100 \%$ light or dark ( $0 \%$ light). For the light-dark transition test, after the acclimation, $10 \mathrm{~min}$ each of tracking in the following conditions: (1) 100\% light followed by (2) dark in succession. The locomotor activity of larvae was measured as the total distance travelled in millimetres (mm) over a 10-min period.

For thigmotaxis, the following parameters were measured: (1) distance spent in inner zone, (2) distance spent in outer zone and (3) distance in entire arena. Thigmotaxis was calculated as percentages using the following formula [42]:

Thigmotaxis $(\%$ distance in outer zone $)=\frac{(\text { Distance outer zone })}{(\text { Distance outer }+ \text { inner zone })} \times 100$

\section{Startle Response to Dark Flashes}

To trigger a startle response in larvae, 150-ms-long dark flashes were used, and this was repeated severally to assess the ability of the larvae to habituate. The startle response test was made up of three steps: (1) 15-min acclimatisation period in $100 \%$ illuminated test chamber, (2) 10-min baseline locomotor tracking in the fully illuminated test chamber, (3) followed by the presentation of 30 dark flashes repeated every $3 \mathrm{~s}$ [43].

\section{Locomotor Activity of Drug-Treated Larvae}

Larvae were pre-exposed 30 min to RISP, HALO or VPA and their respective vehicle control groups, transferred to the test chamber and tracking started immediately for $4 \mathrm{~h}$ at a $30-\mathrm{min}$ integration period. Only tracks after $2 \mathrm{~h}$ were used for analysis. For the 24-h RISP-treated group, larvae were pre-exposed to treatment $22 \mathrm{~h}$ then transferred to the test chamber and tracked immediately for $4 \mathrm{~h}$ with the tracks after $2 \mathrm{~h}$ used for analysis. Larvae were tracked in $100 \%$ light condition and the locomotor activity of larvae were measured as the total distance travelled in millimetres over a $30-\mathrm{min}$ period. Vehicle control and drug-treated larvae were from the same clutch. 


\section{Acoustic Startle Response (ASR) and Prepulse Inhibition (PPI)}

Acoustic stimuli were delivered using the ZebraBox Revo and the behavioural response analysed with EthoVision software as previously described [44] using larvae aged 6 dpf. All experiments were performed by placing larvae individually in each well of a custom-made plexiglass plate of 33 wells in a 96 format. Acclimation was for $5 \mathrm{~min}$ prior to the onset of experiment in a 100-Lx illuminated chamber. The startle stimulus was $100 \mathrm{~ms}$ at $660 \mathrm{~Hz}$ while the prepulse stimulus was $5 \mathrm{~ms}$ at $440 \mathrm{~Hz}$. A 100-ms inter-stimulus interval (ISI) was used for PPI experiments.

\section{Zebrafish EEG Recordings}

The EEG recordings were performed as previously described by Afrikanova et al. [45]. Epileptiform-like discharges were detected by inserting a glass electrode filled with artificial cerebrospinal fluid $(124 \mathrm{mM} \mathrm{NaCl}, 2 \mathrm{mM} \mathrm{KCl}, 2 \mathrm{mM}$ $\mathrm{MgSO}_{4}, 2 \mathrm{Mm} \mathrm{CaCl}_{2}, 1.25 \mathrm{mM} \mathrm{KH}_{2} \mathrm{PO}_{4}, 26 \mathrm{mM} \mathrm{NaHCO}_{3}$, $10 \mathrm{mM}$ glucose) into the optic tectum of individual 6-dpf zebrafish larvae for $20 \mathrm{~min}$ (MultiClamp 700B amplifier, Digidata 1550 digitiser, Axon instruments, USA). The larvae were restrained with the aid of a thin layer of $2 \%$ low melting point agarose. The Clampfit version 10.6.2 software (Molecular Devices Corporation, USA) was used for processing the EEG recordings. The data were analysed manually by a trained observer, blind to the genotype of the larvae.

\section{RNA Isolation and CDNA Synthesis}

Total RNA was isolated from a pool of 6-dpf larvae $(N=25$ larvae, 3 replicates/group) using the Invitrogen PureLink RNA Mini Kit (12183018A, Thermofischer). A Nanodrop 1000 spectrophotometer and agarose bleach gel described by [46] was used to assess the quality/integrity of the RNA. cDNA was synthesised from $1 \mu \mathrm{g}$ RNA with oligo dT primers using the Invitrogen SuperScript IV Reverse Transcriptase (18090050, Thermofischer) according to the manufacturer's instructions.

\section{Reverse Transcriptase and Quantitative Polymerase Chain Reaction}

rt-PCR was performed for 40 cycles using Taq-polymerase (EP0406, Thermofischer) in a $20 \mu \mathrm{l}$ final reaction using $1 \mu \mathrm{l}$ of cDNA template. PCR products were visualised on $2 \%$ agarose gels. The qPCR reactions were performed with Power SYBR Green Master Mix (4368702, Thermofischer) on the CFX384 Touch Real-Time PCR Detection System (1855485, Bio Rad). All primers were synthesised by Sigma with melting temperature $>60^{\circ} \mathrm{C}$. Samples were run in triplicates in a
$20 \mu \mathrm{l}$ final volume containing $10 \mu \mathrm{l} 2 \times$ sybr green, $1 \mu \mathrm{l}$ $10 \mu \mathrm{M}$ forward + reverse primer and $9 \mu 1$ 1:180 cDNA dilution. The following cycling parameters were used: $95^{\circ} \mathrm{C}$ for $10 \mathrm{~min}$, and then 40 cycles of $95^{\circ} \mathrm{C}$ for $15 \mathrm{~s}, 60^{\circ} \mathrm{C}$ for $1 \mathrm{~min}$. To check for the presence of non-specific products and/or primer dimers, a dissociation step was performed at the end of each amplification phase from 65 to $95{ }^{\circ} \mathrm{C}$, at $0.5^{\circ} \mathrm{C}$ increment for $5 \mathrm{~s}$. The comparative $\Delta \Delta \mathrm{CT}$ method was calculated using the Bio Rad CFX Manager 3.1. The endogenous genes glyceraldehyde-3-phosphate dehydrogenase (gapdh) and ribosoamal protein S18 (rps18) were used for data normalisation. See Suppl. Table 1 for the list of rt-/q-PCR primer sequences.

\section{Statistical Analysis}

Statistical analysis and figures generation were performed with the aid of GraphPad Prism 8.4.1 (San Diego, CA, USA). For behavioural experiments, a two-way analysis of variance (ANOVA) (factors: phase/treatment and genotype), followed by Tukey's post hoc test, was used. For EEG experiment, Student's $t$ test was applied. Unpaired Student's $t$ test or its equivalent non-parametric test, Mann Whitney $U$, was performed where necessary. Statistical significance was established at $p<0.05$. In figures, dots represent individual measurements.

\section{Results}

\section{Genotyping and Molecular Consequences of the cacna1da Splice Site Mutation}

As mentioned earlier, the amino acid sequence of zebrafish Cacnalda and Cacnaldb are $77 \%$ and $33 \%$ homologous to human CACNA1D protein respectively. cacnalda has two transcript variants while cacnaldb has a single transcript $[28,29]$. The cacnalda transcript variant 202 spans 47 exons (Fig. 1a), whereas variant 201 spans 48 exons (not shown). The sa17298 allele contains a single point mutation $(\mathrm{G}>\mathrm{A})$ at the first residue of intron 20-21 of the cacnalda-202 transcript variant (Fig. 1b). Importantly, it does not alter the sequence of variant 201. To identify mutants, PCR of larval and/or adult fin clip tissue was digested using BstEII restriction enzyme. The BstEII restriction site is absent in the mutant allele. Hence, $2 \%$ agarose gel electrophoresis of the digested product resulted in one band for homozygous sa17298 ( 196 bp), two bands for WT sa17298 ( 70 and $129 \mathrm{bp}$ ) and three bands for heterozygous sal7298 ( 70, 129 and 196 bp) (Fig. 1c).

To assess whether the splice site mutation resulted in exon skipping, rt-PCR, followed by agarose gel electrophoresis, was performed using primers spanning exons 20-22 of cacnalda transcript variant 202. No difference in product size 
was observed between WT and homozygous mutants, thus suggesting that the mutation did not result in exon skipping. Notably, however, a difference in signal intensity of the rtPCR amplicons was observed (Fig. 1d). Given the difference in signal intensity obtained from WT and homozygotes, we next tested whether the mutation altered mRNA levels. We performed qPCR analysis using three cacnalda primer sets. The first primer set [cacnalda_qPCR] amplified a region with high complementarity between the 201 and 202 transcript variants, the second primer set [E20-22_v202] targeted only the 202 transcript while the third primer set [E22-24_v201] targeted only the 201 transcript (Suppl. Fig. 1). qPCR analysis revealed an overall reduction of cacnalda mRNA levels (ca. $50 \%$ and $40 \%$ ) in heterozygous and homozygous mutants respectively. Primer-specific amplification of variant 202 showed a 50\% and $90 \%$ decrease in transcript 202 levels in heterozygous and homozygous mutants respectively. Interestingly, when primers specifically targeting transcript

\section{a}

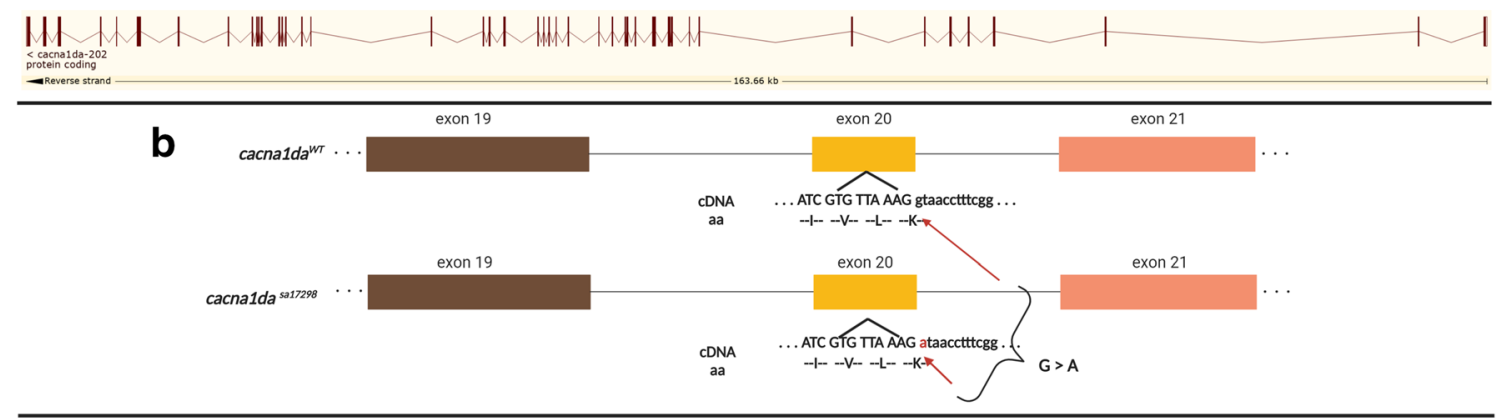

C $+/-$ - $/-$ +/- $+/-\quad+/+\quad \mathrm{L} \quad+/-\quad-/-\quad-/-\quad+/-\quad+/-$

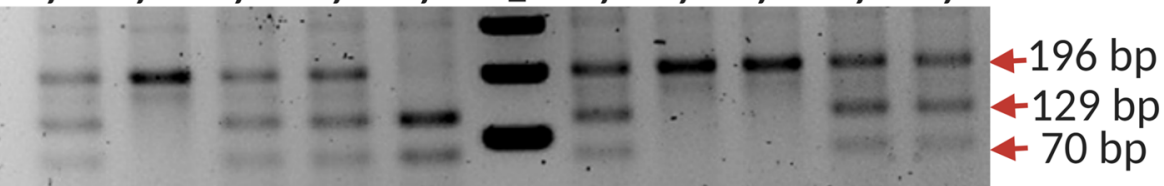
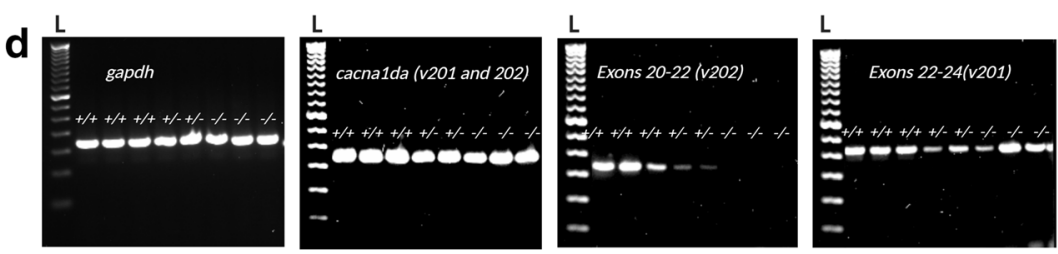

$L=50 \mathrm{bp}$ DNA ladder

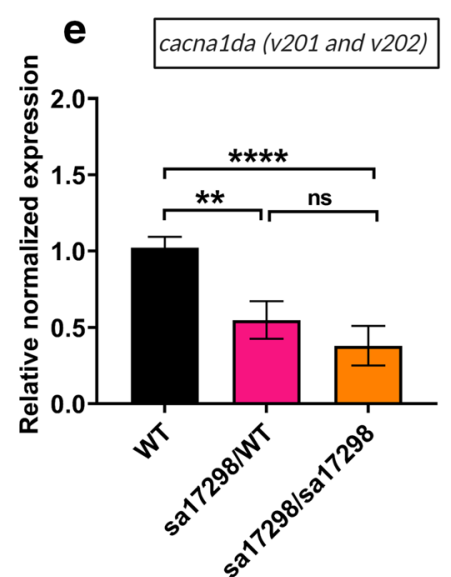

Fig. 1 Zebrafish cacnalda mutant allele (sa17298) and its molecular consequence. a Schematic representation of the zebrafish cacnalda transcript. Red bars represent exons and lines represent introns. Image retrieved from ensembl.org. b Schematic representation of zebrafish cacnalda and sa17298 mutation. Nucleotides in upper case are within the exon while those in lower case are within the intron. c Sample gel electrophoresis of BstEII restriction digest and resulting PCR products to determine genotype of fish/larvae. BstEII does not cut homozygous
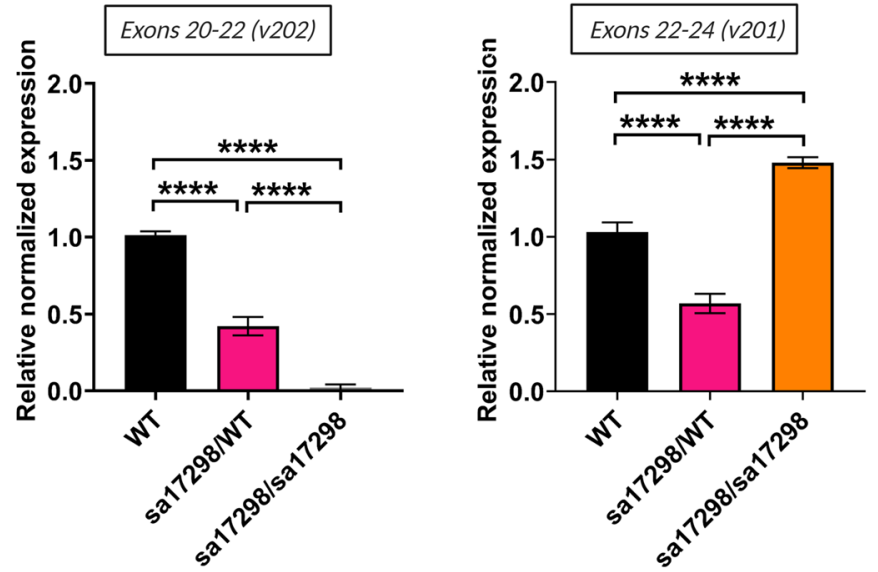

sa17298, but cuts WT into two bands (70 and $119 \mathrm{bp}$ ) and heterozygous sa17298 into three bands (70, 119 and $196 \mathrm{bp})$. Note the multiple bands in the BstEII digested versus the undigested corresponding samples. L: 1 kilobase DNA ladder, +/+: cacnalda ${ }^{W T /}$ WT,+- : cacnalda ${ }^{\text {sal7298/WT }},-/-$ : cacnalda ${ }^{\text {sal7298/sal7298 }}$. d cacnalda mRNA levels as measured by agarose gel electrophoresis (rt-PCR). e cacnalda mRNA levels as measured by qPCR. cacnalda mRNA expression is normalised against gapdh and $r p s 18$ 


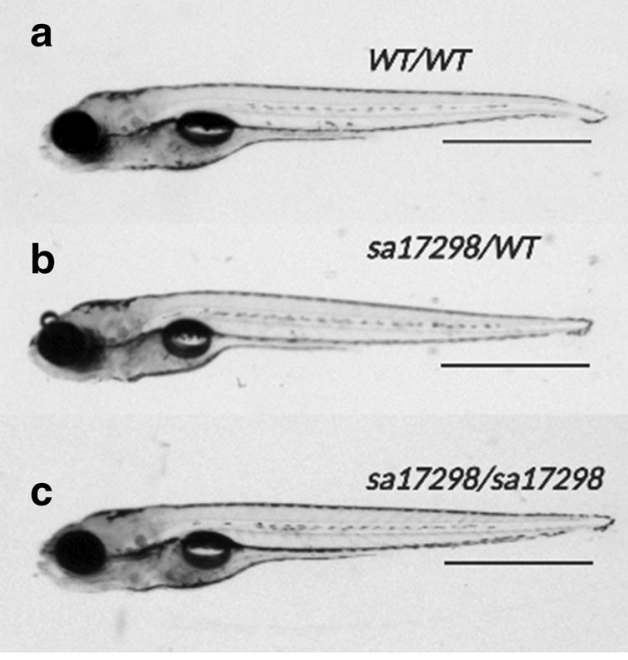

Fig. 2 Morphology of a WT cacnalda $a^{W T / W T}$ b heterozygous cacnalda ${ }^{\text {sal7298/WT }}$ and $\mathbf{c}$ homozygous cacnalda $a^{\text {sal7298/sal7298 }}$. Both heterozygous and homozygous mutants are morphologically indistinguishable from WT siblings. Scale bar $(\mathrm{a}-\mathbf{c}): 1 \mathrm{~mm}$

variant 201 were used, homozygous mutants showed a $50 \%$ increase, while heterozygous mutants showed a $50 \%$ reduction in levels of variant 201 (Fig. 1e).

\section{Morphological Analysis of sa17298 Mutants}

When AB-outcrossed mutants were bred, the resulting heterozygous and homozygous mutants were morphologically indistinguishable from their WT siblings (Fig. 2). All experiments were carried out using the $\mathrm{AB}$ outcrossed fish. ${ }^{1}$ Based on genotyping results, less than $5 \%$ of homozygous sa17298 larvae survived until adulthood. No impairment in the touchevoked response of heterozygous and homozygous sal 7298 larvae was observed when compared to WT (data not shown).

\section{Acoustic Startle Response and Prepulse Inhibition}

Four different auditory stimuli $(40,50,60,70 \mathrm{~dB})$ at $660 \mathrm{~Hz}$ were tested to determine the suitable startle stimuli, and it was determined that $70 \mathrm{~dB}$ evoked the strongest startle response at $p<0.05$ (Fig. 3a). When a $50-\mathrm{dB}$ prepulse preceded the $70-\mathrm{dB}$ stimulus, larval startle response was decreased (Fig. 3b). Oneway ANOVA revealed no statistically significant difference in the PPI (\%) between WT and either mutant genotype (i.e. heterozygotes and homozygotes) (Fig. $3 \mathrm{c})[F(2,16)=$

\footnotetext{
${ }^{1}$ It is important to note that gross morphological defects such as craniofacial abnormalities, smaller, fused or absent eyes, curved body axis, yolk sac necrosis and hyperpigmentation were visible as early as $2 \mathrm{dpf}$ in a proportion of the offspring $(\sim 25 \%)$ when male and female adult heterozygous sa17298 (obtained directly from ZIRC) were in-crossed. These morphological defects were present in heterozygous and homozygous $5 a 17298$ populations as well as WT larvae (Suppl. Fig. 2). We therefore recommend that the line be outcrossed over multiple generations to remove other mutations that may confound the interpretation of results.
}

$1.403, p=0.2745]$. Notably, however, there was a tendency of homozygotes towards statistical significance (i.e. increased PPI).

\section{Locomotor Assessment of sa17298 Larvae}

To determine if the sa17298 mutation modulates locomotor behaviour, one batch of larvae were tracked in dark conditions ( $0 \%$ light) while another group of larvae were tracked in $100 \%$ light. Mann Whitney $U$ test showed no statistically significant difference between the genotypes $\left[\right.$ cacnalda ${ }^{W T / W T}(\mathrm{Mdn}=$

a

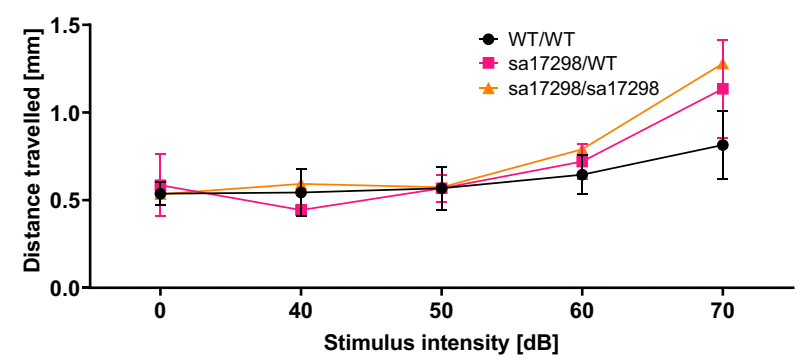

b

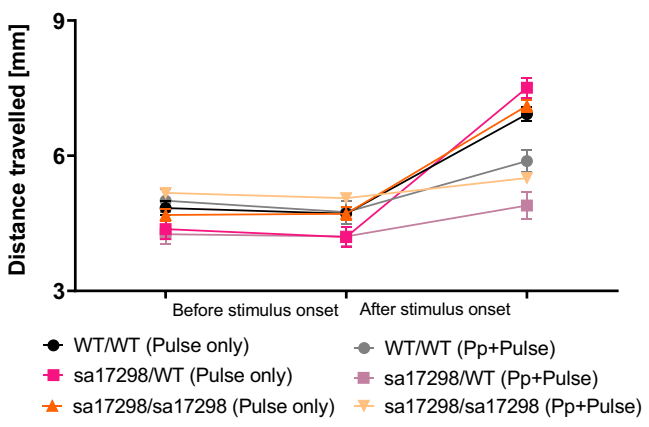

C

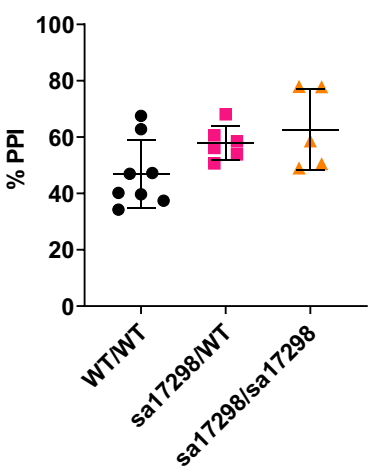

Fig. 3 Acoustic startle response and PPI. a Graph of distance travelled when presented with different auditory stimuli. Data analysed using twoway ANOVA and presented as mean \pm SEM. b Preceding a startle with a prepulse stimulus decreases the startle response of larvae. Data shown as mean \pm SEM. c \% PPI of larvae. One-way ANOVA revealed no overall significant difference among the groups. Tukey's multiple comparison post hoc test however showed a strong tendency of homozygous mutant larvae towards significance (i.e. enhanced PPI). cacnalda ${ }^{W T / W T}(N=8)$, cacnalda $a^{\text {sal7298/WT }}$ $(N=6)$ and cacnald $a^{\text {sal }}$. $298 /$ sal $7298(N=5), p>0.05$. Error bars represent mean \pm SD. ASR, acoustic startle response; Pp, prepulse; PPI, prepulse inhibition. cacnalda ${ }^{W T / W T}$ vs cacnaldasa17298/WT $: p=0.2002$, cacnalda $^{W T / W T}$ vs cacnalda ${ }^{\text {sal7298/sal 7298 }}: p=0.0646$, cacnald $a^{\text {sal } 7298 /}$ ${ }^{W T}$ vs cacnalda $a^{\text {sal7298/sal7298 }}: p=0.7702$ 
2155, $N=16)$ and cacnalda $^{\text {sal } 7298 / W T}(\mathrm{Mdn}=2027, N=15)$; $U=109, p=0.6823$ ] when tracked in the dark (Fig. 4a). On the other hand, when larvae where tracked in $100 \%$ light conditions, Mann Whitney $U$ test indicated that the total distance travelled by cacnalda ${ }^{W T / W T}(\mathrm{Mdn}=1632, N=21)$ was significantly lower than cacnalda ${ }^{\text {sal7298/WT }}(\mathrm{Mdn}=2039, N=22)$; $U=92, p=0.0005]$ (Fig. 4b).

\section{Larval Behaviour in Response to Abrupt Change in Illumination}

The locomotor behaviour of larval zebrafish differs depending on light-dark transitions [47]. Based on the observations made when two groups of larvae were independently tracked in either light or dark conditions, we hypothesised that changes in illumination in the tracking chamber would alter locomotor activity of sa17298 larvae. We analysed spontaneous swimming after a 15-min acclimation period. Swimming in each illumination state (light-dark) was recorded for $10 \mathrm{~min}$ (Fig. 5).

In Fig. 5 a, larvae demonstrated an increased locomotor activity when transitioned from light to dark shown by a non-RM two-way ANOVA analysis [genotype $F(1,28)=$ 9.645, $p<0.01$; illumination $F(1,28)=162.3, p<0.0001$; interaction $F(1,28)=3.241, p=0.0826]$. Tukey's post hoc test revealed that both cacnalda $a^{W T / W T}(p<0.0001)$ and cacnalda ${ }^{\text {sa17298/WT }}(p<0.0001)$ travelled higher distances in the dark than in the light. Additionally, the post hoc test indicated statistical significance between cacnalda $a^{W T W T}$ and cacnalda ${ }^{\text {sa17298/WT }}$ when they transitioned to the dark $(p<0.01)$, whereas Student's $t$ test showed statistical significant difference between cacnalda ${ }^{W T W T}$ and cacnalda $a^{\text {sal7298/ }}$ ${ }^{W T}$ in the light phase $(p<0.05)$.

A previous study reported that changes in illumination altered the zone preference of larvae in the thigmotaxis test [42].
Therefore, we sought to determine if changes in illumination modulated the zone preference of cacnalda $a^{W T W T}$ and cacnalda ${ }^{\text {sal7298/WT }}$ larvae. Larvae were assessed for the distance travelled (\%) in the outer zones of a 24-well plate arena within $10 \mathrm{~min}$.

As seen in Fig. 5b, there was no significant difference in the zone preference of cacnalda ${ }^{W T / W T}$ and cacnalda ${ }^{\text {sa17298/WT }}$ larvae using non-RM two-way ANOVA analysis in the light-dark transition [genotype $F(1,28)=0.1310, p=0.7201$; illumination $F(1,28)=$ $0.4996, p=0.4855$; interaction $F(1,28)=0.01618, p=$ $0.8997]$.

\section{Assessment of Startle Response to Repetitive Dark Flashes}

Zebrafish larvae respond to startle stimuli such as unexpected light or sound stimulus and quantifying changes in distance travelled have been established as a suitable readout of startle response [43, 48]. Following the "startle response to a dark flash" protocol of Norton, larvae were presented with 30 dark flashes repeated every $3 \mathrm{~s}$ [43].

The locomotor activity of the last $21 \mathrm{~s}$ of the 10 -min basal locomotor activity was measured preceding the dark flashes that were every $3 \mathrm{~s}$ thirty times (Fig. 6a). In general, cacnalda ${ }^{W T W T}$ and cacnalda $a^{\text {sal7298/WT }}$ larvae neither swum the same distance during 21 -s basal locomotor activity [ $t$ $(41)=3.879, p=0.0004$, Fig. 6a] nor the 90-s startle experiment $[t(41)=2.627, p=0.0120$, Fig. 6b].

The distance moved in response to the first and second dark flash was greater than the distance moved in response to subsequent stimuli. Whereas WT larvae showed signs of habituation after the 2 nd stimulus, habituation was only visible after the 19th stimulus in heterozygous mutants. Multiple $t$ test analysis showed that at several time points, cacnalda $^{\text {sal7298/ }}$
Fig. 4 Locomotor activity of WT and heterozygous sa17298 zebrafish larvae at $6 \mathrm{dpf}$, tracked independently under different illumination conditions. a Tracking in the dark reveals no difference in locomotor activity between cacnalda ${ }^{W T / W T}(N=16)$ and cacnalda $a^{\text {sal7298/WT }}(N=15)$. b Tracking in $100 \%$ light reveals a statistically significant difference in locomotor activity between cacnalda ${ }^{W T W T}(N=21)$ and cacnalda $a^{\text {sal 7298/WT }}(N=22)$. $* * * p<0.001$. Data analysed using Mann Whitney $U$ test and represented as mean $\pm \mathrm{SD}$
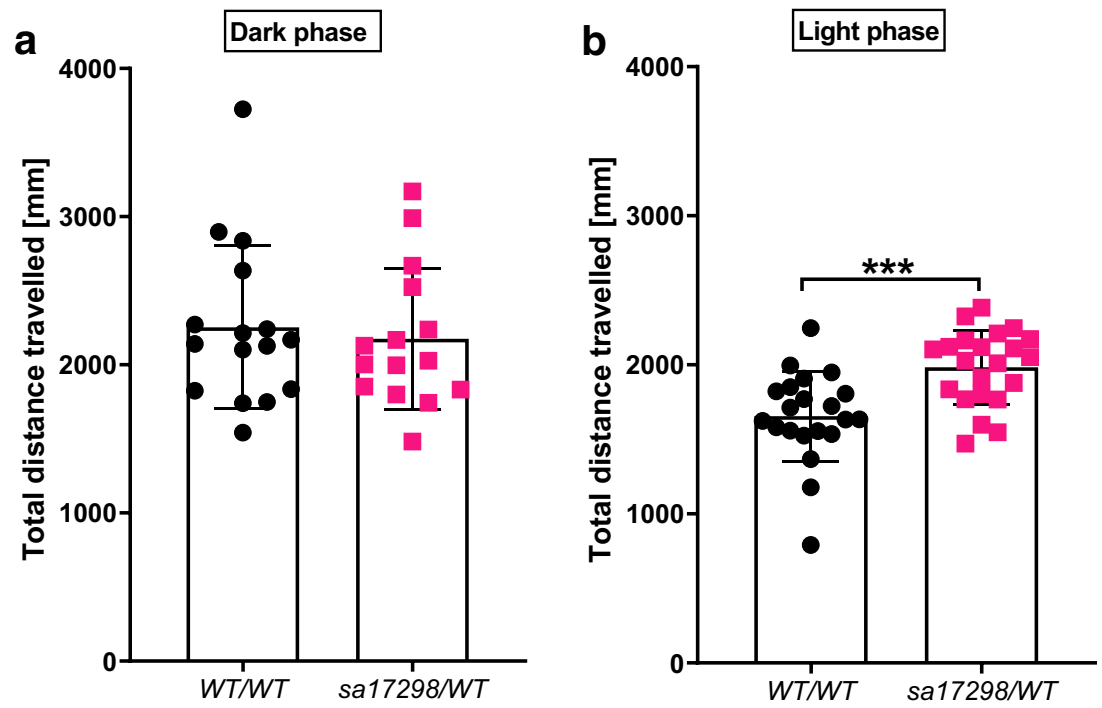
${ }^{W T}$ larvae were significantly more active than cacnalda ${ }^{W T W T}$ at $p<0.05$. Overall, cacnald $a^{\text {WTWT }}$ displayed a robust startle response relative to baseline than cacnalda ${ }^{\text {sal7298/WT }}$ [i.e. when we compared the last $21 \mathrm{~s}$ prior to stimulus onset with startle stimuli response] (Fig. 6c).

\section{Effects of Neuroactive Drugs on the Locomotor Activity of WT and Heterozygous sa17298 Zebrafish Larvae}

In zebrafish, hyperlocomotion is often characterised as a phenotype of epilepsy- [45, 49-52], anxiety- [51, 53] or psychosis-like behaviour [51, 54, 55]. To understand the possible cause of the hyperlocomotor behaviour, we observed in heterozygous sa17298/WT larvae, three neuroactive drugs i.e. RISP, HALO and VPA were evaluated for their ability to modulate the larval hyperactivity after $30 \mathrm{~min}$ of tracking. Non-RM two-way ANOVA revealed a significant effect of both genotype $[F(1,56)=8.010, p=0.0064]$ and treatment $[F(1,56)=5.799, p=0.0193]$ on locomotor activity when larvae were exposed to $5 \mu \mathrm{M}$ RISP for $2 \mathrm{~h}$. No significant interaction $[F(1,56)=1.066, p=0.3064]$ was observed. However, a Tukey's post hoc test showed that RISP was only effective in decreasing the locomotor activity of sa17298/WT $(p<0.05)$ but not WT/WT $(p>0.05)$ when compared with their untreated control (Fig. 7a).

To ascertain whether a prolonged exposure of zebrafish larvae to RISP would enhance RISP's effectiveness in affecting locomotor activity, a set of larvae were incubated in RISP for $24 \mathrm{~h}$ and the locomotor activity measured subsequently. As seen in Fig. 7b, non-RM two-way ANOVA showed an overall statistically significant effect of RISP on larval locomotor activity after 24-h pre-exposure [genotype $[F(1,36)=$ $10.77, p=0.0023]$; treatment $[F(1,36)=51.41, p<0.0001]$; interaction $[F(1,36)=1.351, p=0.2527]]$. Tukey's post hoc test revealed a statistically significant decrease in locomotor activity in larvae treated with $5 \mu \mathrm{M}$ RISP when compared with their untreated control at least $p<0.01$ such that baseline locomotor activity became comparable between $5 \mu \mathrm{M}$ [WT/ WT vs sal7298/WT] at $p=0.4262$.

Furthermore, two-way non-RM ANOVA of larvae exposed to $50 \mu \mathrm{M}$ HALO for $2 \mathrm{~h}$ (Fig. 7c) yielded a statistically significant effect of genotype $[F(1,45)=15.03, p=0.0003]$ and treatment $[F(1,45)=78.55, p<0.0001]$ on locomotor activity with no significant interaction $[F(1,45)=1.518, p=$ $0.2243]$. Subsequent Tukey's post hoc analysis revealed a reduction in locomotor activity of the $50 \mu \mathrm{M}$ treated larvae when compared to their respective within group control at least $p<0.001$. There was no statistical significance observed between $50 \mu \mathrm{M}[\mathrm{WT} / \mathrm{WT}$ vs sal7298/WT] at $p=0.3117$.

In Fig. 7d, larvae pre-treated in VPA for $2 \mathrm{~h}$ displayed an overall significant effect of genotype $[F(1,60)=33.15$, $p<0.0001]$ and treatment $[F(1,60)=23.57, p<0.0001]$ on
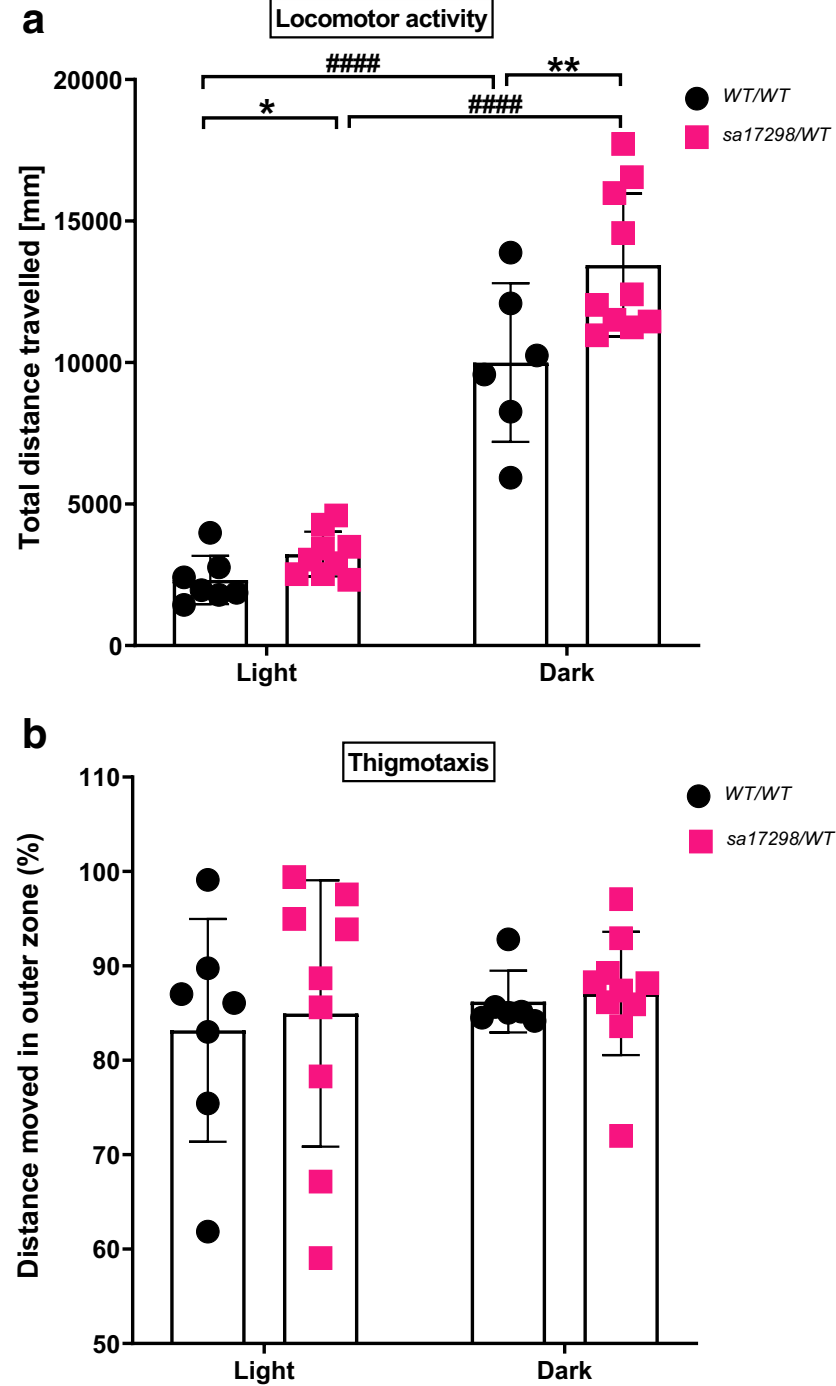

Fig. 5 Behaviour of WT and heterozygous sal 7298 zebrafish larvae at $6 \mathrm{dpf}$ in the light-dark transition test. Each dot represents an individual larval measurement. Data analysed using non-RM two-way ANOVA followed by Tukey's post hoc test. Data represented as mean \pm SD. a Light-dark transition elicits an increase in locomotor activity in both genotypes with locomotor difference between cacnalda ${ }^{W T / W T}$ and cacnald $a^{\text {sal7298/WT }}$ reaching statistical significance in both illumination states. * $(p<0.05), * *(p<0.01)$ : [cacnalda ${ }^{W T / W T}$ vs cacnalda $\left.{ }^{\text {sal } 7298 / W T}\right]$ in the dark, \#\#\# $(p<0.0001):\left[\right.$ cacnalda ${ }^{W T W T}$ vs cacnalda $\left.{ }^{W T / W T}\right]$ and $\left[\right.$ cacnalda ${ }^{\text {sal7298/WT }}$ vs cacnalda ${ }^{\text {sal7298/WT }}$. b Zone preference of WT and heterozygous sa17298 larvae (thigmotaxis) represented as \% total distance moved in the outer zone in the light-dark transition test

larval locomotor activity with no significant interaction $[F$ $(1,60)=0.1149, p=0.7358]$ observed when a two-way nonRM ANOVA was performed. Tukey's post hoc analysis showed statistically significant effect of VPA to decrease larval locomotor activity across groups at least $p<0.01$ when compared with untreated larvae of the same genotype. However, VPA was unable to reduce the hyperlocomotion of sa17298/WT larvae to a comparable level as the VPAtreated WT/WT group $(p=0.0023)$. 


\section{Effects of Neuroactive Drugs on the Behaviour of WT and Heterozygous sa17298 Zebrafish Larvae in the Light-Dark Test}

The hyperlocomotor activity of heterozygous larvae relative to WT in the light and dark states was reversed after the exposure of larvae to all the treatment options i.e. 24-h exposure in $5 \mu \mathrm{M}$ RISP and 2-h exposure in $5 \mu \mathrm{M}$ RISP, $50 \mu \mathrm{M}$ HALO and $100 \mu \mathrm{M}$ VPA at $p>0.05$. Larvae in either genotypes exposed to all the treatment groups but HALO were capable of eliciting a light-dark response by increasing their locomotion $(p<0.001)$ (See Fig. 8 and Suppl. Table 2). a

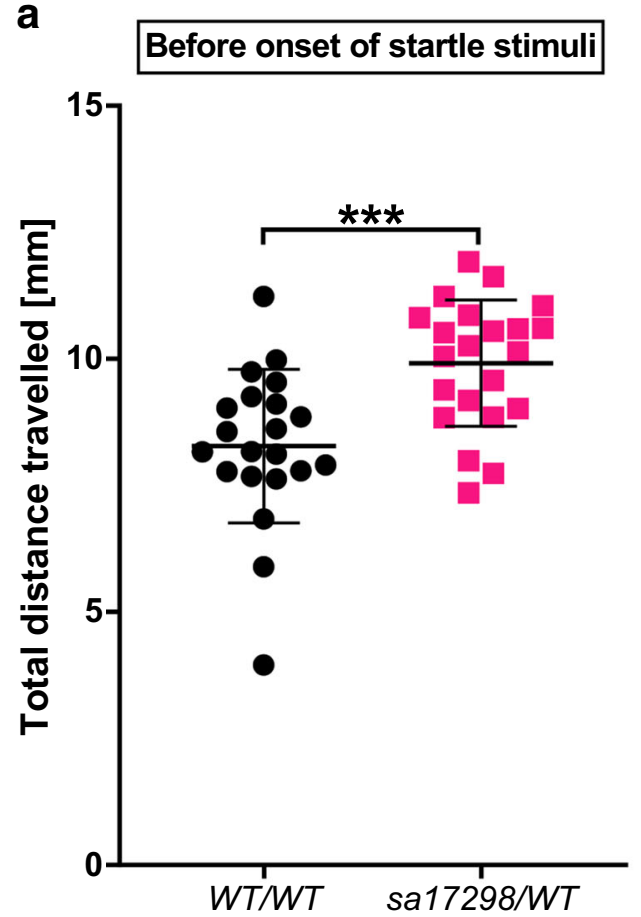

b

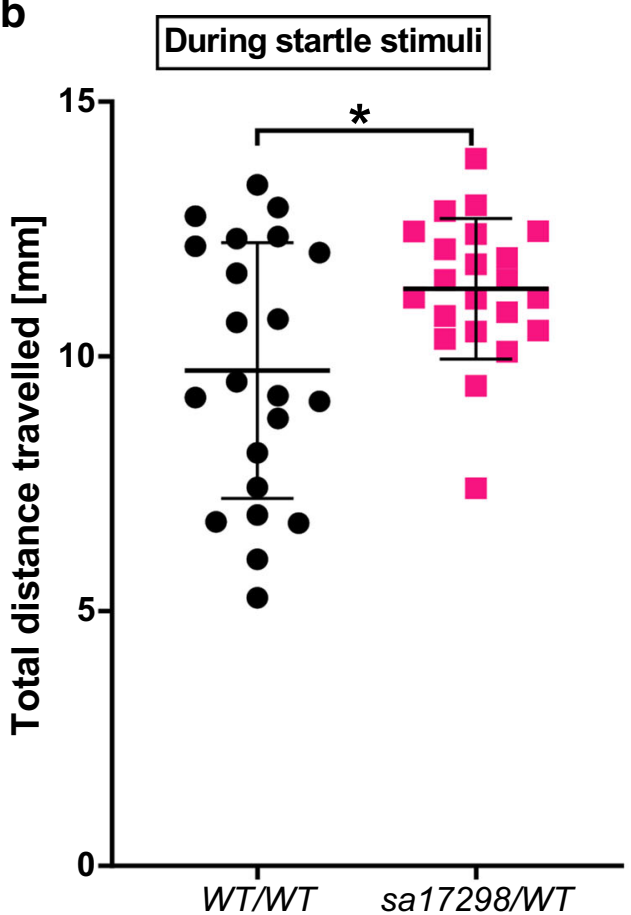

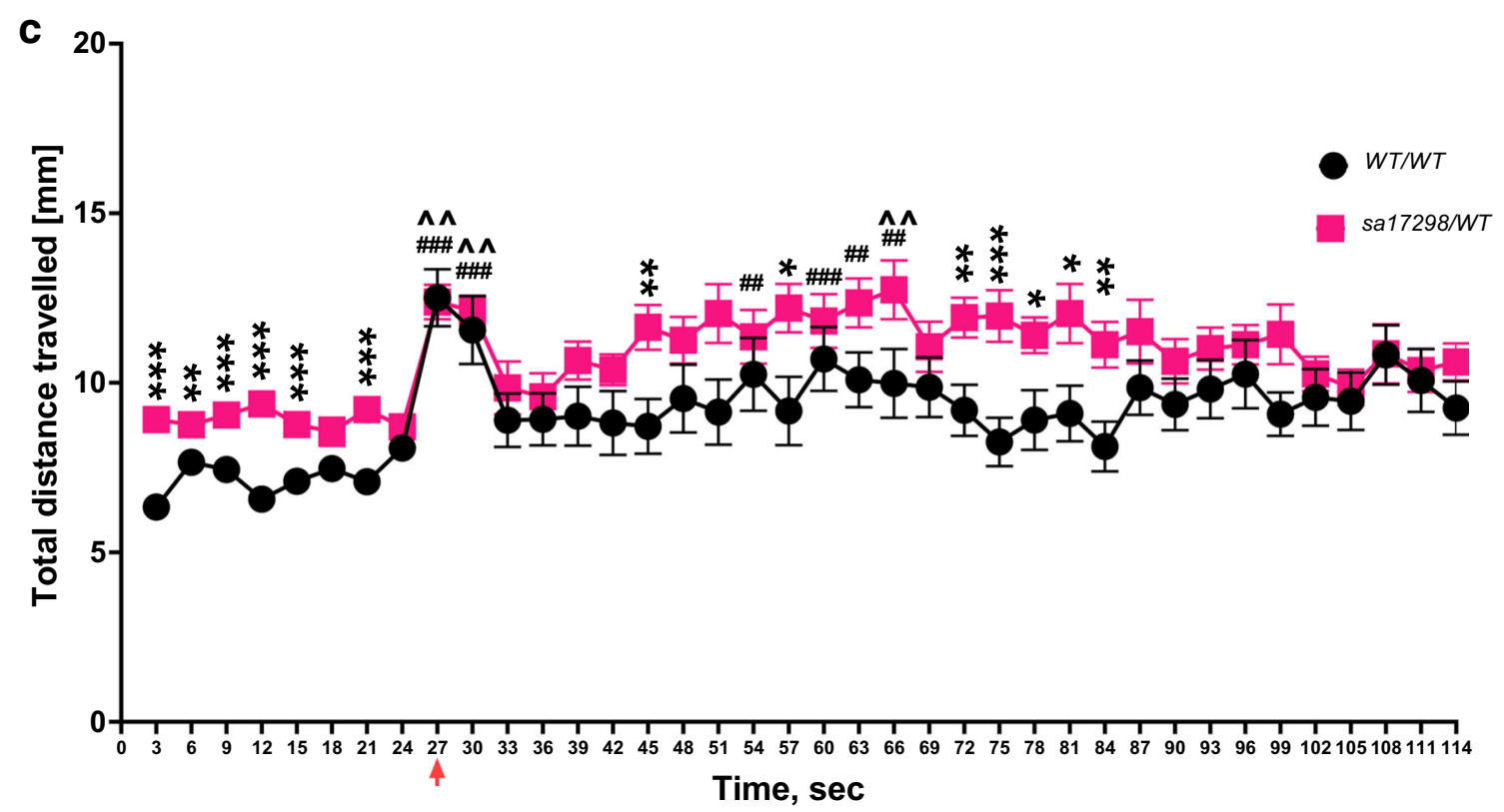

Fig. 6 Startle response to dark flashes. a Baseline locomotor activity $21 \mathrm{~s}$ prior to onset of startle stimuli, $* * * p<0.001$. Data represented as mean \pm SD. b Mean distance moved in response to startle stimuli. Unpaired Student's $t$ test showed cacnalda $a^{W T / W T}$ moved less than cacnalda ${ }^{\text {sal7298/WT }}$ during the 90 -s startle stimulation, $* p<0.05$. Data represented as mean $\pm \mathrm{SD}$. c Distance moved in response to startle stimuli represented as mean \pm SEM. Paired Student's $t$ test analysis between cacnalda ${ }^{W T / W T}$ and cacnalda ${ }^{\text {sal7298/WT }}$ with statistical significance represented as ${ }^{*} p<0.05,{ }^{\#} p<0.01,{ }^{\wedge} p<0.001$. Red arrow: onset of startle stimulus (dark flashes) 

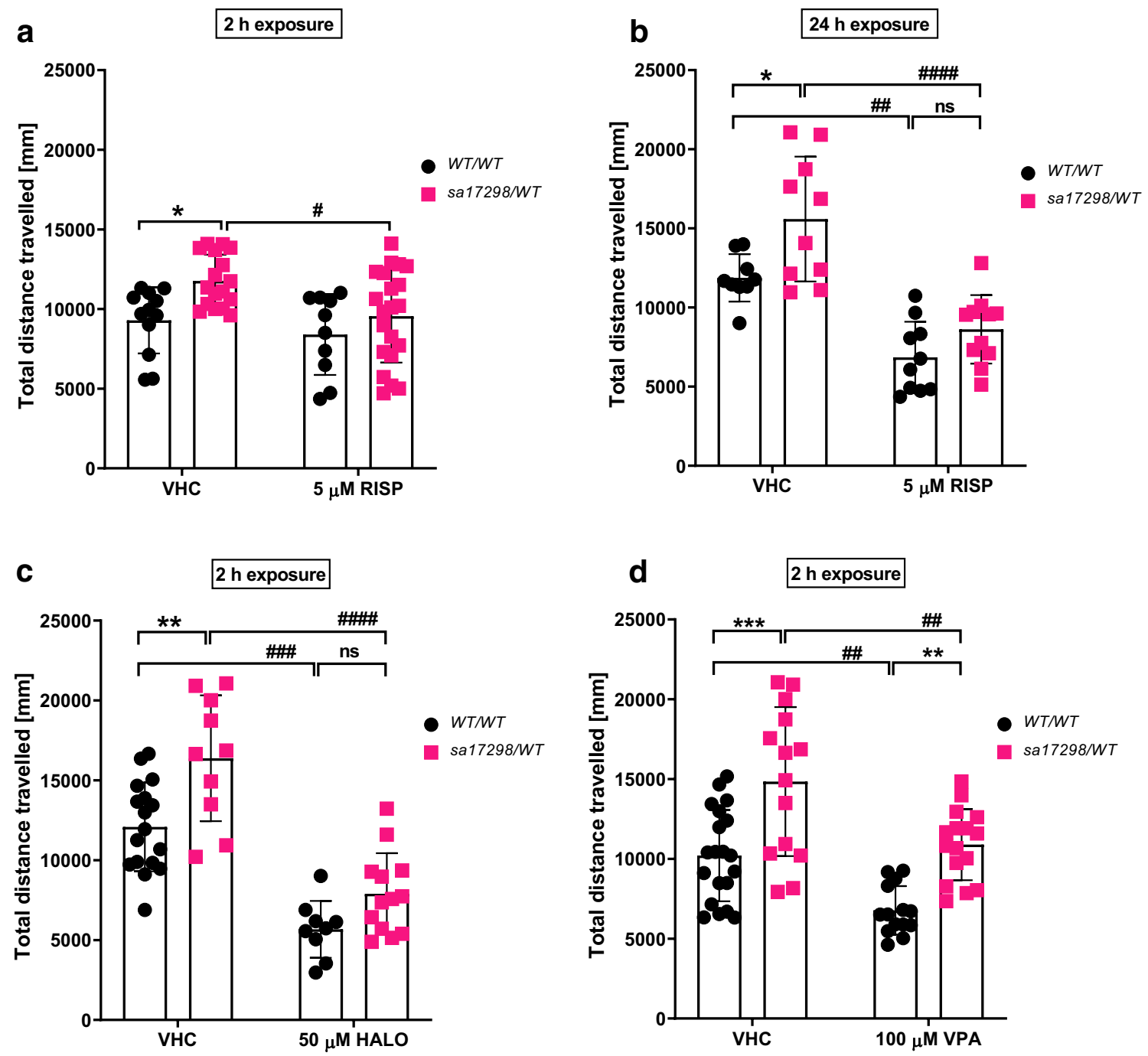

Fig. 7 Effects of neuroactive drugs on the locomotor activity of 6-dpf WT and heterozygous sa17298 larvae. Larvae were exposed to different neuroactive drugs. Each dot represents individual larval measurement. Data analysed using non-RM two-way ANOVA followed by Tukey's post hoc test. Data represented as mean \pm SD. a 2-h RISP, b

\section{Effects of Neuroactive Drugs on the Behaviour of WT and Heterozygous sa17298 Zebrafish Larvae in the Startle Response to Dark Flashes}

Larvae treated in vehicle control behaved similarly as their untreated (medium) counterparts previously described. In the 2-h exposure to RISP group, there was no difference in locomotor activity between WT and heterozygous mutant larvae prior to the onset of the dark flashes. After dark flashes onset, there was reduced startle response of heterozygous larvae in the first five dark stimuli with the next seven dark flashes resulting in comparable behaviour to the untreated group. In general, RISP at $2 \mathrm{~h}$ reduced heterozygous larval reactivity to the startle inducing dark flashes ( $p>0.05$, Fig. 9a). At 24-h exposure, RISP reversed the hyperlocomotor activity of heterozygous larvae prior to the onset of dark stimuli $(p>0.05$,

24-h RISP c 2-h HALO and d 2-h VPA. HALO, haloperidol; RISP, risperidone; VPA, valproic acid. $* p<0.05, * * p<0.01, * * * p<0.001$ $\left[\right.$ cacnalda ${ }^{W T / W T}$ vs cacnalda $\left.{ }^{\text {sal } 298 / W T}\right]$ in respective groups. ${ }^{\#} p<0.05$, ${ }^{\# \#} p<0.01,{ }^{\# \#} p<0.001,{ }^{\# \# \# p<0.0001}\left[\right.$ [cacnalda ${ }^{W T W T}$ vs cacnalda ${ }^{W T /}$ ${ }^{W T}$ ] and [cacnalda $a^{\text {sal7298/WT }}$ vs cacnalda sa17298/WT $^{\text {cos }}$

Fig. 9b). However, upon onset of dark flashes, heterozygous larvae behaved similar to their untreated siblings i.e. hyperactivity ( $p<0.01$, Fig. $9 \mathrm{~b}$ ). On the other hand, HALO was able to reverse the hyperlocomotor activity of heterozygous larvae both prior to and at the presentation of the startle inducing dark flashes ( $p>0.05$, Fig. 9c). Whereas, VPA treatment resulted in a delayed response of larvae to dark flashes and an overall reversal of hyperactivity of the heterozygous larvae ( $p>0.05$, Fig. 9d) (For modulatory activity of all drugs over time, see Suppl. Fig. 3 and Table 3).

\section{EEG Assessment}

Student's $t$ test analysis of tectal EEG recordings of 6-dpf larvae indicated that there were no statistically significant differences with regard to the number of epileptiform-like 
discharges between cacnalda ${ }^{W T / W T}(M=2.088, N=12)$ and cacnalda $^{\text {sa17298/WT }}(M=4.333, N=15) ; t(25)=0.8741, p=$ 0.3904 (for example, see Suppl. Fig. 4).

\section{Discussion}

In this study, we describe for the first time neurobehavioural changes in larval zebrafish with an essential splice variant mutation (sal7298) in the cacnalda gene. Since our mutant (sa17298) harbours a single point mutation $(\mathrm{G}>\mathrm{A})$ at the donor splice site of intron 20-21 of the cacnalda-202 transcript variant, we anticipated that this could lead to
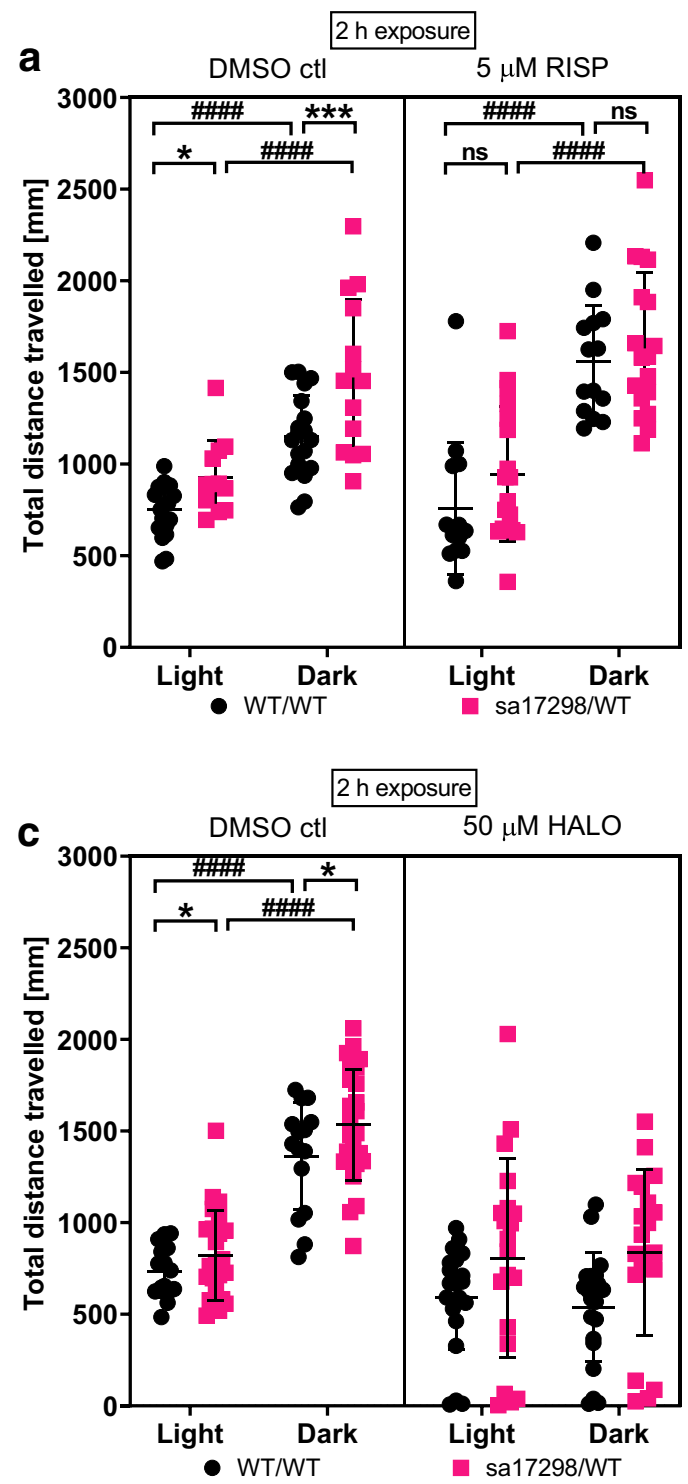

Fig. 8 Effects of neuroactive drugs on the behaviour of 6-dpf WT and heterozygous sa17298 larvae in the light-dark test. Larvae were exposed to different neuroactive drugs. Each dot represents individual larval measurement. Data analysed using two-way ANOVA followed by multiple comparison $t$ test. Data represented as mean \pm SD. a 2-h RISP, b 24-h dysregulation of cacnalda mRNA or protein expression, thus mimicking classical GOF or loss-of-function mutations. Agarose gel electrophoresis of rt-PCR products did not suggest exon skipping as a consequence of the mutation. The results showed significantly reduced "overall" cacnalda mRNA and 202 transcript levels in both heterozygous and homozygous mutants relative to WT. For the 201 transcript, while heterozygous mutants showed reduced levels, homozygous mutants on the contrary showed increased levels. We speculate that the sa17298 splice variant mutation leads to a premature termination codon in variant 202 , as a result of intron retention, thereby resulting in nonsense-mediated decay, thus resulting in loss or significant reduction of this
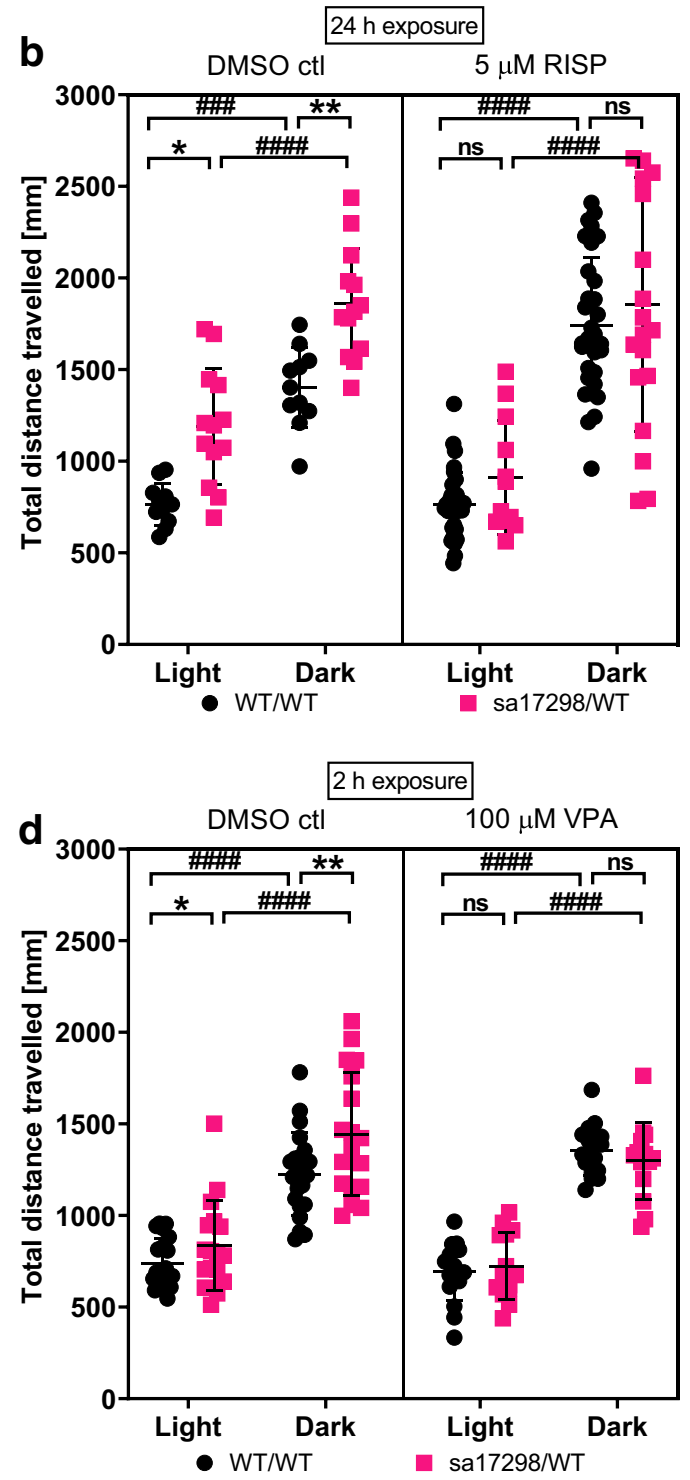

RISP, c 2 h HALO and d 2-h VPA. ctl, control; HALO, haloperidol; RISP, risperidone; VPA, valproic acid. $* p<0.05, * * p<0.01$, $* * * p<0.001$ [cacnalda ${ }^{W T / W T}$ vs cacnalda ${ }^{\text {sal7298/WT }}$ in respective groups. ${ }^{\# \# \#} p<0.001,{ }^{\# \# \# ~} p<0.0001\left[\right.$ cacnalda ${ }^{W T / W T}$ vs cacnalda ${ }^{W T /}$ $\left.{ }_{W T}\right]$ and [cacnalda $a^{\text {sal7298/WT }}$ vs cacnalda $\left.{ }^{\text {sal7298/WT }}\right]$ 
particular transcript and subsequent compensation through an increase in levels of transcript variant 201.

Our study revealed significant behavioural impairments in cacnalda $a^{\text {sa17298/WT }}$ mutants when assayed for locomotor activity (under light conditions), during light-dark transition and in the startle response to dark flashes. However, we did not observe significant PPI deficits, thigmotaxis-related abnormalities or epileptiform-like discharges in larval brains as measured by EEG recordings.

The behavioural response of cacnalda ${ }^{W T / W T}$ in the lightdark stimulus task is in agreement with other studies [41,
56-59], which showed an abrupt increase in locomotor activity of larvae during rapid switching from light to dark. Kedra et al. [56] revealed that homozygous tsc2-deficient larvae (model of tuberous sclerosis complex, in which $90 \%$ of patients display seizures) exhibited the same behavioural response as described here for cacnalda $a^{\text {sa17298/WT }}$ mutants i.e. a pronounced increase in locomotor activity of $t s c 2^{-1-}$ larvae compared with their control counterparts in the dark phase of the light-dark stimulus task. $t s c 2^{-/-}$larvae also displayed increased thigmotaxis as well as a preference to light phase in the light-dark preference task. Exacerbation of thigmotactic
Fig. 9 Time series graph of the effects of neuroactive drugs on the behaviour of 6-dpf WT and heterozygous sal7298 larvae in the startle response to dark flashes test. Larvae were exposed to different neuroactive drugs. Each dot represents individual larval measurement. Data represented as mean \pm SEM. a 2-h RISP, b 24-h RISP, c 2-h HALO, d 2-h VPA. HALO, haloperidol; RISP, risperidone; VPA, valproic acid
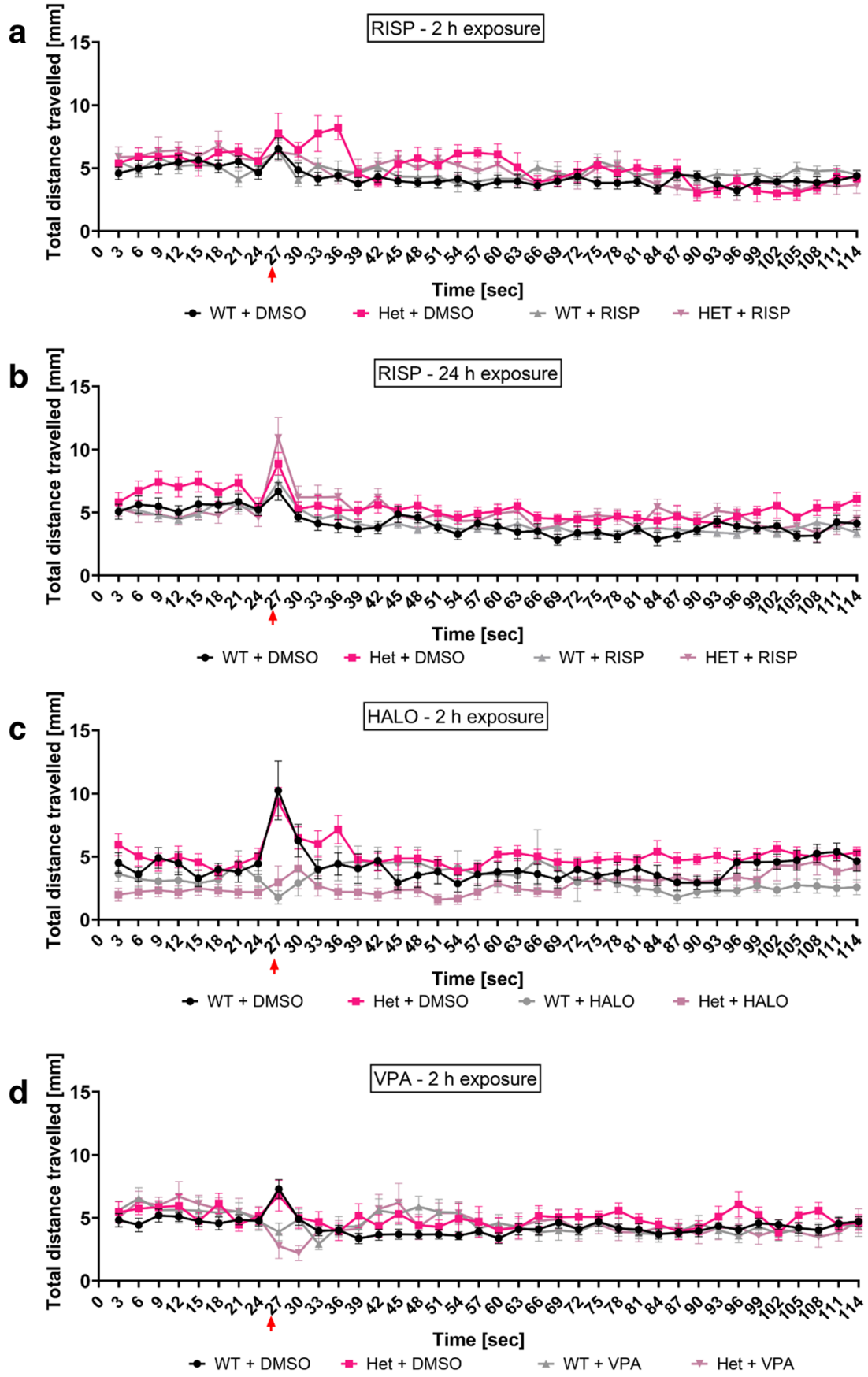
behaviour in zebrafish during dark phase is regarded as a marker of anxiety-like behaviour [42, 60], thus indicating an anxiety-like phenotype for $t s 2^{-/-}$larvae. In contrast, we did not observe changes in thigmotaxis between cacnalda genotypes. Thus, it is unlikely that the increased locomotor activity of cacnalda ${ }^{\text {sal }}{ }^{7298 / W T}$ larvae in the dark phase of the lightdark stimulus task was a result of cacnalda-mediated anxietylike behaviour.

Increased locomotor activity, as a readout of tonic-cloniclike seizures, was previously described in zebrafish genetic models of epilepsy [49, 61, 62], which correlated well with the occurrence of epileptiform-like discharges in larval brains as measured by EEG. In some human CACNA1D mutation carriers, different types of seizures have been observed (focal and/or generalised seizures) [17, 20, 63]. In our study, we observed epileptiform-like discharges in the EEG assay only in 3 out of 15 cacnalda ${ }^{\text {sal7298/WT }}$ larvae. Thus, it is unlikely that the hyperlocomotion displayed by cacnalda ${ }^{\text {sal7298/WT }}$ mutants is associated with seizures.

CACNA1D mutations have been implicated earlier in SCZ $[8,13,21]$. In behavioural pharmacology in rodents, the most common approach is to mimic psychotic-like positive symptoms by administering drugs that target $\mathrm{N}$-methyl-D-aspartate (NMDA) (antagonism) or dopaminergic (agonism) receptors. These drugs induce psychosis in rodents with hyperactivity as a readout of this symptom (for review, see [64]). Interestingly, pharmacological studies revealed high correlation with regard to the ability of larval and adult zebrafish to mimic positive SCZ symptoms. For example, ketamine [65, 66] and MK-801 (also called dizocilpine) $[54,67]$ induce a robust increase in locomotion. Moreover, d-amphetamine or $\mathrm{D}_{2}$ receptor agonists elicit the same locomotor response in adult zebrafish $[68,69]$ as in rodents [70-74]. Previously, hyperlocomotion was observed in mouse genetic models of SCZ with mutations in Discl [75] and $\mathrm{Nrgl}$ [76]. In larval zebrafish, this feature was also commonly observed in mutants harbouring mutations in different genes indicated by GWAS as SCZ susceptibility genes [77]. A study by Thyme et al. [77], which generated and analysed 132 different mutants of SCZ-risk genes, showed that hyperlocomotion was sometimes observed in a number of these fish.

To obtain further insight into the neurobehavioural changes in cacnalda ${ }^{\text {sal7298/WT }}$ larvae, we evaluated sensorimotor gating and habituation in larvae by performing two tests-i.e. ASR and PPI tests, as well as the startle response to dark flashes assay. The startle response to dark flashes assay, in which animals habituate to dark flashes when exposed to continuous light stimulus, allows for the assessment of nonassociative memory [43, 48, 78, 79], which is also impaired in most schizophrenic patients [80,81]. The ASR and PPI are the most commonly used tasks in $\mathrm{SCZ}$ research with an altered PPI response observed in schizophrenia patients [82-85], rodent [86-88] and some zebrafish models of SCZ [77]. The difference between PPI and startle response to dark flashes is the type of stimulus-i.e. auditory versus visual. As CACNA1D mutations have been previously implicated in deafness in humans [89, 90], mice [24] and even zebrafish [34], we assessed the hearing sensitivities of larvae across genotypes using different stimulus intensities (sound) and found them to be comparable. Nevertheless, no difference in PPI between WT and heterozygous mutants was observed, albeit with tendency of homozygotes towards enhanced PPI. The very low survival rate of homozygotes proved prohibitive with regard to our ability to collect and assay a sufficiently large set of larvae to reach statistical significance in our experimental setup. To the best of our knowledge, there is a lack of data as to whether $C A C N A 1 D$ mutation carriers are blind or have other visual deficits. However, a study reported Cacnald knockout mice to have slight visual impairment but found no evidence that this affected their behaviour in the Morris water maze test (a "visual" spatial learning and memory task) [25]. In the zebrafish, in situ hybridisation analysis revealed expression of cav1.3a mRNA in the eye (although faint) and ear, while cav1.3b expression was evident in the otic vesicle of 5dpf larvae. qPCR analysis indicated expression of cav1.3a mRNA both in the eyes and ears of adult zebrafish [27]. Taking into account that interlarval behavioural patterns were consistent throughout all experiments, we postulate that mutant visual acuity is preserved and that the behavioural phenotypes observed are a result of changes in brain activity and not visual disturbances. Although it appears that the cacnalda $a^{\text {sa17298/WT }}$ mutant response in this assay (startle response to dark flashes) might be related to cognitive symptoms of $\mathrm{SCZ}$, this aspect of the mutant phenotype needs further investigation. Additionally, since the CACNA1D gene is duplicated in the zebrafish [27], the severity of the mutation may be attenuated through partial compensation by $c a c n a l d b$. Thus, this may explain the absence of PPI deficits in the mutants.

We performed pharmacological profiling of WT and cacnalda ${ }^{\text {sal7298/WT }}$ larvae in the locomotor (under constant illumination), light-dark and startle response to dark flashes tests after exposure to different neuroactive drugs: two drugs used in the management of SCZ (HALO and RISP) and one drug (VPA) indicated for the treatment of epilepsy, and as add-on therapy in BP, migraine, anxiety or SCZ. The behavioural response of our WT fish after incubation with all 3 drugs is in agreement with previous studies which showed that all of them decreased locomotor activity in both larval and adult animals [35, 36, 54, 58, 91-93]. It seems that the response of WT larvae (i.e. hypoactivity) is a common feature for antipsychotics, as other drugs from this group also decreased baseline activity in WT larvae (e.g. droperidol, phenothiazine or clozapine) [94, 95]. With regard to VPA exposure, our study indicated that this drug substantially decreased activity of cacnalda $a^{\text {sa17298/WT }}$ larvae in all the three 
behavioural tests, although heterozygous mutants were significantly more active than their WT siblings in the locomotor test. The mechanism of action of VPA includes increasing levels of $\gamma$-aminobutyric acid (GABA) in the brain, inhibition of histone deacetylase and blockage of voltage-gated ion channels (sodium, potassium and calcium), such as $\mathrm{CaV}_{1.3}$ [96-98]. We therefore theorise that the effectiveness of VPA in decreasing locomotor activity in cacnalda mutants may act through a different mechanism other than seizure suppression.

In humans, CACNAID mRNA has been detected in limbic and mesolimbic structures (i.e. amygdala, hippocampus, thalamus, hypothalamus, basal ganglia) [101, 102], which are enriched with dopaminergic neurons. Similarly, in mice, the Cacnald gene is expressed in limbic and striatal areas [103-105]. Sidi et al. [27] observed that the expression of cav1.3a is detected as early as 30 -h post-fertilisation (hpf) in the zebrafish brain (telencephalon, thalamic and hypothalamic diencephalon, midbrain, ventral hindbrain). From $48 \mathrm{hpf}$ onwards, expression of cav1.3a becomes even more pronounced in almost the entire brain [27].

In conclusion, different zebrafish genetic models of epilepsy and to a lesser extent, SCZ, have emerged within the last 5 years (for comprehensive reviews see [106, 107]). Although the zebrafish brain is less complex than the mammalian one, fish are very sensitive to neuroactive compounds and their behavioural responses are easily tracked in 48 -well plates. This allows for very rapid and efficient screening of compounds compared with rodents, thus enabling the identification of bioactive "hit" compounds for further investigation. Thus far, only zebrafish genetic models of epilepsy have been used successfully for discovering new therapeutic options in high-throughput screening assays [49, 108]. In SCZ research, there remains a need for identification of new antipsychotic agents with less side effects (especially those related to extrapyramidal symptoms) and effectiveness in alleviating negative and cognitive symptoms besides positive symptoms. Furthermore, with the advancements in genetic engineering methods in zebrafish [109-111], there is potential for using a precision medicine-based approach, where patient-specific mutations are introduced into zebrafish embryos to generate "customised" models for drug screening. This may aid scientists in tackling the pharmaco-resistance problem prevalent in SCZ patients, of which genetics plays a key role [see reviews [112, 113]. In relation to cacnalda ${ }^{\text {sa17298/WT }}$ larvae, our data appears promising, but further in-depth phenotyping is warranted to fully validate it as a new model of Cacnald-mediated SCZ.

Authors' Contributions NSB, CVE and KG conceptualised the experiments. All authors contributed to preparation of the manuscript. NSB and CVE revised and edited the final version. NSB carried out all larval morphological assessment, behavioural phenotyping and corresponding data analysis. LDW assisted with behavioural experiments. KG performed EEG experiments and analysis. NSB and KG prepared the figures. All authors read and approved the manuscript.

Funding Open Access funding provided by University of Oslo (incl Oslo University Hospital). This work was funded by the Research Council of Norway (ISP, BIOTEK2021/ DigiBrain) (for NSB and CVE) and partially supported by start-up funds from the Centre for Molecular Medicine Norway (for CVE). KG was funded by the European Union's Horizon 2020 research and innovation programme under the Marie SkłodowskaCurie (grant agreement No. 798703-GEMZ-H2020-MSCA-IF-2017).

Compliance with Ethical Standards All experiments were approved by the Norwegian Food Safety Authority experimental animal administration's supervisory and application system (FOTS-18/106800-1; ID 15469 and 23935).

Conflict of Interest The authors declare that they have no conflict of interest.

Open Access This article is licensed under a Creative Commons Attribution 4.0 International License, which permits use, sharing, adaptation, distribution and reproduction in any medium or format, as long as you give appropriate credit to the original author(s) and the source, provide a link to the Creative Commons licence, and indicate if changes were made. The images or other third party material in this article are included in the article's Creative Commons licence, unless indicated otherwise in a credit line to the material. If material is not included in the article's Creative Commons licence and your intended use is not permitted by statutory regulation or exceeds the permitted use, you will need to obtain permission directly from the copyright holder. To view a copy of this licence, visit http://creativecommons.org/licenses/by/4.0/.

\section{References}

1. Ripke S, Neale BM, Corvin A et al (2014) Biological insights from 108 schizophrenia-associated genetic loci. Nature 511:421427. https://doi.org/10.1038/nature13595

2. Harrison PJ (2015) Recent genetic findings in schizophrenia and their therapeutic relevance. J Psychopharmacol 29:85-96. https:// doi.org/10.1177/0269881114553647

3. Hawi Z, Tong J, Dark C, Yates H, Johnson B, Bellgrove MA (2018) The role of cadherin genes in five major psychiatric disorders: a literature update. Am J Med Genet 177:168-180. https:// doi.org/10.1002/ajmg.b.32592

4. Maurano MT, Humbert R, Rynes E, Thurman RE, Haugen E, Wang H, Reynolds AP, Sandstrom R et al (2012) Systematic localization of common disease-associated variation in regulatory DNA. Science 337:1190-1195. https://doi.org/10.1126/science. 1222794

5. Gershon ES, Grennan K, Busnello J, Badner JA, Ovsiew F, Memon S, Alliey-Rodriguez N, Cooper J et al (2014) A rare mutation of CACNA1C in a patient with bipolar disorder, and decreased gene expression associated with a bipolar-associated common SNP of CACNA1C in brain. Mol Psychiatry 19:890894. https://doi.org/10.1038/mp.2013.107

6. Bigos KL, Mattay VS, Callicott JH, Straub RE, Vakkalanka R, Kolachana B, Hyde TM, Lipska BK et al (2010) Genetic variation in CACNA1C affects brain circuitries related to mental illness. Arch Gen Psychiatry 67:939-945. https://doi.org/10.1001/ archgenpsychiatry.2010.96 
7. Yoshimizu T, Pan JQ, Mungenast AE, Madison JM, Su S, Ketterman J, Ongur D, McPhie D et al (2015) Functional implications of a psychiatric risk variant within CACNA1C in induced human neurons. Mol Psychiatry 20:162-169. https://doi.org/10. 1038/mp.2014.143

8. Andrade A, Brennecke A, Mallat S, Brown J, Gomez-Rivadeneira J, Czepiel N, Londrigan L (2019) Genetic associations between voltage-gated calcium channels and psychiatric disorders. Int J Mol Sci:20. https://doi.org/10.3390/ijms20143537

9. Chan CS, Guzman JN, Ilijic E, Mercer JN, Rick C, Tkatch T, Meredith GE, Surmeier DJ (2007) "Rejuvenation" protects neurons in mouse models of Parkinson's disease. Nature 447:10811086. https://doi.org/10.1038/nature05865

10. Puopolo M, Raviola E, Bean BP (2007) Roles of subthreshold calcium current and sodium current in spontaneous firing of mouse midbrain dopamine neurons. J Neurosci 27:645-656. https://doi.org/10.1523/JNEUROSCI.4341-06.2007

11. Zamponi GW, Striessnig J, Koschak A, Dolphin AC (2015) The physiology, pathology, and pharmacology of voltage-gated calcium channels and their future therapeutic potential. Pharmacol Rev 67:821-870. https://doi.org/10.1124/pr.114.009654

12. Oguro-Okano M, Griesmann GE, Wieben ED et al (1992) Molecular diversity of neuronal-type calcium channels identified in small cell lung carcinoma. Mayo Clin Proc 67:1150-1159. https://doi.org/10.1016/S0025-6196(12)61144-6

13. Cross-Disorder Group of the Psychiatric Genomics Consortium (2013) Identification of risk loci with shared effects on five major psychiatric disorders: a genome-wide analysis. Lancet 381:13711379. https://doi.org/10.1016/S0140-6736(12)62129-1

14. Kabir ZD, Martínez-Rivera A, Rajadhyaksha AM (2017) From gene to behavior: L-type calcium channel mechanisms underlying neuropsychiatric symptoms. Neurotherapeutics 14:588-613. https://doi.org/10.1007/s13311-017-0532-0

15. Pinggera A, Striessnig J (2016) Cav 1.3 (CACNA1D) L-type $\mathrm{Ca} 2+$ channel dysfunction in CNS disorders. J Physiol Lond 594:5839-5849. https://doi.org/10.1113/JP270672

16. Hofer NT, Tuluc P, Ortner NJ, Nikonishyna YV, FernándesQuintero ML, Liedl KR, Flucher BE, Cox H et al (2020) Biophysical classification of a CACNA1D de novo mutation as a high-risk mutation for a severe neurodevelopmental disorder. Mol Autism 11. https://doi.org/10.1186/s13229-019-0310-4

17. Pinggera A, Lieb A, Benedetti B, Lampert M, Monteleone S, Liedl KR, Tuluc P, Striessnig J (2015) CACNA1D De novo mutations in autism spectrum disorders activate Cav1.3 L-type calcium channels. Biol Psychiatry 77:816-822. https://doi.org/10. 1016/j.biopsych.2014.11.020

18. Pinggera A, Mackenroth L, Rump A, Schallner J, Beleggia F, Wollnik B, Striessnig J (2017) New gain-of-function mutation shows CACNA1D as recurrently mutated gene in autism spectrum disorders and epilepsy. Hum Mol Genet 26:2923-2932. https://doi.org/10.1093/hmg/ddx 175

19. Pinggera A, Negro G, Tuluc P, Brown MJ, Lieb A, Striessnig J (2018) Gating defects of disease-causing de novo mutations in Cav1.3 Ca2+ channels. Channels (Austin) 12:388-402. https:// doi.org/10.1080/19336950.2018.1546518

20. Scholl UI, Goh G, Stölting G, de Oliveira RC, Choi M, Overton JD, Fonseca AL, Korah R et al (2013) Somatic and germline CACNA1D calcium channel mutations in aldosterone-producing adenomas and primary aldosteronism. Nat Genet 45:1050-1054. https://doi.org/10.1038/ng.2695

21. Devor A, Andreassen O, Wang Y et al (2017) Genetic evidence for role of integration of fast and slow neurotransmission in schizophrenia. Mol Psychiatry 22:792-801. https://doi.org/10. 1038/mp.2017.33

22. Ross J, Gedvilaite E, Badner JA, Erdman C, Baird L, Matsunami N, Leppert M, Xing J et al (2016) A rare variant in CACNA1D segregates with 7 bipolar I disorder cases in a large pedigree. Mol Neuropsychiatry 2:145-150. https://doi.org/10.1159/000448041

23. Guan F, Li L, Qiao C, Chen G, Yan T, Li T, Zhang T, Liu X (2015) Evaluation of genetic susceptibility of common variants in CACNA1D with schizophrenia in Han Chinese. Sci Rep 5:12935. https://doi.org/10.1038/srep12935

24. Platzer J, Engel J, Schrott-Fischer A, Stephan K, Bova S, Chen H, Zheng H, Striessnig J (2000) Congenital deafness and sinoatrial node dysfunction in mice lacking class D L-type Ca2+ channels. Cell 102:89-97. https://doi.org/10.1016/s0092-8674(00)00013-1

25. Busquet P, Khoi Nguyen N, Schmid E, Tanimoto N, Seeliger MW, Ben-Yosef T, Mizuno F, Akopian A et al (2010) CaV1.3 L-type $\mathrm{Ca} 2+$ channels modulate depression-like behaviour in mice independent of deaf phenotype. Int J Neuropsychopharmacol 13: 499-513. https://doi.org/10.1017/S1461145709990368

26. McKinney BC, Sze W, Lee B, Murphy GG (2009) Impaired longterm potentiation and enhanced neuronal excitability in the amygdala of CaV1.3 knockout mice. Neurobiol Learn Mem 92:519528. https://doi.org/10.1016/j.nlm.2009.06.012

27. Sidi S, Busch-Nentwich E, Friedrich R, Schoenberger U, Nicolson $\mathrm{T}$ (2004) Gemini encodes a Zebrafish L-type calcium channel that localizes at sensory hair cell ribbon synapses. J Neurosci 24 :42134223. https://doi.org/10.1523/JNEUROSCI.0223-04.2004

28. http://www.ensemble.org Gene: cacna $1 \mathrm{da}$ (ENSDARG00000102773) - Orthologue alignment - Danio rerio - Ensembl genome browser 99. https://www.ensembl.org/Danio rerio/Gene/Compara_Ortholog/Alignment?db=core;g= ENSDARG00000102773; g1=ENSG00000157388;hom_id= 449865216;r=11:36793473-36963988. Accessed 23 Apr 2020

29. http://www.ensemble.org Gene: cacna $1 \mathrm{db}$ (ENSDARG00000075917) - Orthologue alignment - Danio rerio - Ensembl genome browser 99. https://www.ensembl.org/Danio rerio/Gene/Compara_Ortholog/Alignment?db=core;g= ENSDARG00000075917;g1=ENSG00000142609; hom_id= 560456301;r=8:53204017-53260670. Accessed 23 Apr 2020

30. Nicolson T (2015) Ribbon synapses in zebrafish hair cells. Hear Res 330:170-177. https://doi.org/10.1016/j.heares.2015.04.003

31. Sheets L, Trapani JG, Mo W, Obholzer N, Nicolson T (2011) Ribeye is required for presynaptic CaV1.3a channel localization and afferent innervation of sensory hair cells. Development 138: 1309-1319. https://doi.org/10.1242/dev.059451

32. Sheets L, Kindt KS, Nicolson T (2012) Presynaptic CaV1.3 channels regulate synaptic ribbon size and are required for synaptic maintenance in sensory hair cells. J Neurosci 32:17273-17286. https://doi.org/10.1523/JNEUROSCI.3005-12.2012

33. Granato M, van Eeden FJ, Schach U, Trowe T, Brand M, Furutani-Seiki M, Haffter P, Hammerschmidt M et al (1996) Genes controlling and mediating locomotion behavior of the zebrafish embryo and larva. Development 123:399-413

34. Nicolson T, Rüsch A, Friedrich RW, Granato M, Ruppersberg JP, Nüsslein-Volhard C (1998) Genetic analysis of vertebrate sensory hair cell mechanosensation: the zebrafish circler mutants. Neuron 20:271-283. https://doi.org/10.1016/S0896-6273(00)80455-9

35. Prieto MJ, Gutierrez HC, Arévalo RA, Chiaramoni NS, Alonso SV (2012) Effect of risperidone and fluoxetine on the movement and neurochemical changes of zebrafish. OJMC 02:129-138. https://doi.org/10.4236/ojmc.2012.24016

36. Irons TD, Kelly P, Hunter DL et al (2013) Acute administration of dopaminergic drugs has differential effects on locomotion in larval zebrafish. Pharmacol Biochem Behav 103:792-813. https://doi. org/10.1016/j.pbb.2012.12.010

37. Tremolizzo L, Doueiri M-S, Dong E, Grayson DR, Davis J, Pinna G, Tueting P, Rodriguez-Menendez V et al (2005) Valproate corrects the schizophrenia-like epigenetic behavioral modifications induced by methionine in mice. Biol Psychiatry 57:500-509. https://doi.org/10.1016/j.biopsych.2004.11.046 
38. White HS, Alex AB, Pollock A, Hen N, Shekh-Ahmad T, Wilcox KS, McDonough JH, Stables JP et al (2012) A new derivative of valproic acid amide possesses a broad-spectrum antiseizure profile and unique activity against status epilepticus and organophosphate neuronal damage. Epilepsia 53:134-146. https://doi.org/10.1111/ j.1528-1167.2011.03338.x

39. Sanger Institute Zebrafish Mutation Project (2013) ZFIN Feature: sa17298. https://zfin.org/ZDB-ALT-131217-13434. Accessed 23 Apr 2020

40. Aleström P, D’Angelo L, Midtlyng PJ et al (2019) Zebrafish: housing and husbandry recommendations: laboratory animals. https://doi.org/10.1177/0023677219869037

41. Gawel K, Turski WA, van der Ent W, Mathai BJ, KirsteinSmardzewska KJ, Simonsen A, Esguerra CV (2020) Phenotypic characterization of larval zebrafish (Danio rerio) with partial knockdown of the cacnala gene. Mol Neurobiol 57:1904-1916. https://doi.org/10.1007/s12035-019-01860-x

42. Schnörr S, Steenbergen P, Richardson M, Champagne D (2012) Measuring thigmotaxis in larval zebrafish - ScienceDirect. https:// www.sciencedirect.com/science/article/pii/S0166432811008758? via\%3Dihub. Accessed 5 Dec 2019

43. Norton WHJ (2012) Measuring larval zebrafish behavior: locomotion, thigmotaxis, and startle. In: Kalueff AV, Stewart AM (eds) Zebrafish protocols for neurobehavioral research. Humana Press, Totowa, NJ, pp. 3-20

44. Banono NS, Esguerra CV (2020) Pharmacological validation of the prepulse inhibition of startle response in larval zebrafish using a commercial automated system and software. JoVE:61423. https://doi.org/10.3791/61423

45. Afrikanova T, Serruys A-SK, Buenafe OEM, Clinckers R, Smolders I, de Witte PAM, Crawford AD, Esguerra CV (2013) Validation of the zebrafish pentylenetetrazol seizure model: locomotor versus electrographic responses to antiepileptic drugs. PLoS One 8:e54166. https://doi.org/10.1371/journal.pone. 0054166

46. Aranda PS, LaJoie DM, Jorcyk CL (2012) Bleach gel: a simple agarose gel for analyzing RNA quality. ELECTROPHORESIS 33:366-369. https://doi.org/10.1002/elps.201100335

47. Basnet RM, Zizioli D, Taweedet S, Finazzi D, Memo M (2019) Zebrafish larvae as a behavioral model in neuropharmacology. Biomedicines 7:23. https://doi.org/10.3390/biomedicines7010023

48. Best JD, Berghmans S, Hunt JJFG, Clarke SC, Fleming A, Goldsmith P, Roach AG (2008) Non-associative learning in larval zebrafish. Neuropsychopharmacology 33:1206-1215. https://doi. org/10.1038/sj.npp.1301489

49. Baraban SC, Dinday MT, Hortopan GA (2013) Drug screening in Scn1 a zebrafish mutant identifies clemizole as a potential Dravet syndrome treatment. Nat Commun 4:2410. https://doi.org/10. 1038/ncomms 3410

50. Gawel K, Kukula-Koch W, Nieoczym D, Stepnik K, van der Ent W, Banono NS, Tarabasz D, Turski WA et al (2020) The influence of palmatine isolated from Berberis sibirica radix on pentylenetetrazole-induced seizures in zebrafish. Cells 9:1233. https://doi.org/10.3390/cells9051233

51. Kalueff AV, Gebhardt M, Stewart AM, Cachat JM, Brimmer M, Chawla JS, Craddock C, Kyzar EJ et al (2013) Towards a comprehensive catalog of zebrafish behavior 1.0 and beyond. Zebrafish 10:70-86. https://doi.org/10.1089/zeb.2012.0861

52. Tiraboschi E, Martina S, van der Ent W et al (2020) New insights into the early mechanisms of epileptogenesis in a zebrafish model of Dravet syndrome. Epilepsia 61:549-560. https://doi.org/10. 1111/epi.16456

53. Maximino C, de Brito TM, da Silva Batista AW, Herculano AM, Morato S, Gouveia A Jr (2010) Measuring anxiety in zebrafish: A critical review. Behav Brain Res 214:157-171. https://doi.org/10. 1016/j.bbr.2010.05.031
54. Seibt KJ, da Luz Oliveira R, Zimmermann FF et al (2010) Antipsychotic drugs prevent the motor hyperactivity induced by psychotomimetic MK-801 in zebrafish (Danio rerio). Behav Brain Res 214:417-422. https://doi.org/10.1016/j.bbr.2010.06.014

55. Seibt KJ, Piato AL, da Luz OR et al (2011) Antipsychotic drugs reverse MK-801-induced cognitive and social interaction deficits in zebrafish (Danio rerio). Behav Brain Res 224:135-139. https:// doi.org/10.1016/j.bbr.2011.05.034

56. Kedra M, Banasiak K, Kisielewska K, Wolinska-Niziol L, Jaworski J, Zmorzynska J (2020) TrkB hyperactivity contributes to brain dysconnectivity, epileptogenesis, and anxiety in zebrafish model of tuberous sclerosis complex. Proc Natl Acad Sci U S A 117:2170-2179. https://doi.org/10.1073/pnas.1910834117

57. Scheldeman C, Mills JD, Siekierska A, Serra I, Copmans D, Iyer AM, Whalley BJ, Maes J et al (2017) mTOR-related neuropathology in mutant tsc2 zebrafish: Phenotypic, transcriptomic and pharmacological analysis. Neurobiol Dis 108:225-237. https://doi.org/ 10.1016/j.nbd.2017.09.004

58. Li F, Lin J, Liu X et al (2018) Characterization of the locomotor activities of zebrafish larvae under the influence of various neuroactive drugs. Ann Transl Med 6:173. https://doi.org/10.21037/ atm.2018.04.25

59. Liu X, Zhang Y, Lin J, et al (2016) Frontiers | social preference deficits in juvenile zebrafish induced by early chronic exposure to sodium valproate | Behavioral Neuroscience. https://www. frontiersin.org/articles/10.3389/fnbeh.2016.00201/full. Accessed 5 Dec 2019

60. Lundegaard PR, Anastasaki C, Grant NJ, Sillito RR, Zich J, Zeng Z, Paranthaman K, Larsen AP et al (2015) MEK inhibitors reverse cAMP-mediated anxiety in zebrafish. Chem Biol 22:1335-1346. https://doi.org/10.1016/j.chembiol.2015.08.010

61. Zhang Y, Kecskés A, Copmans D, Langlois M, Crawford AD, Ceulemans B, Lagae L, de Witte PAM et al (2015) Pharmacological characterization of an antisense knockdown zebrafish model of Dravet syndrome: inhibition of epileptic seizures by the serotonin agonist fenfluramine. PLoS One 10: e0125898. https://doi.org/10.1371/journal.pone.0125898

62. Pena IA, Roussel Y, Daniel K et al (2017) Pyridoxine-dependent epilepsy in zebrafish caused by Aldh7a1 deficiency. Genetics genetics.300137.2017. https://doi.org/10.1534/genetics.117.300137

63. Klassen T, Davis C, Goldman A, Burgess D, Chen T, Wheeler D, McPherson J, Bourquin T et al (2011) Exome sequencing of ion channel genes reveals complex profiles confounding personal risk assessment in epilepsy. Cell 145:1036-1048. https://doi.org/10. 1016/j.cell.2011.05.025

64. Jones C, Watson D, Fone K (2011) Animal models of schizophrenia. Br J Pharmacol 164:1162-1194. https://doi.org/10.1111/j. 1476-5381.2011.01386.x

65. Michelotti P, Quadros VA, Pereira ME, Rosemberg DB (2018) Ketamine modulates aggressive behavior in adult zebrafish. Neurosci Lett 684:164-168. https://doi.org/10.1016/j.neulet. 2018.08.009

66. De Campos EG, Bruni AT, De Martinis BS (2015) Ketamine induces anxiolytic effects in adult zebrafish: a multivariate statistics approach. Behav Brain Res 292:537-546. https://doi.org/10. 1016/j.bbr.2015.07.017

67. Chen J, Patel R, Friedman TC, Jones KS (2010) The behavioral and pharmacological actions of NMDA receptor antagonism are conserved in zebrafish larvae. Int J Comp Psychol 23:82-90

68. Kyzar E, Stewart AM, Landsman S, Collins C, Gebhardt M, Robinson K, Kalueff AV (2013) Behavioral effects of bidirectional modulators of brain monoamines reserpine and d-amphetamine in zebrafish. Brain Res 1527:108-116. https://doi.org/10.1016/j. brainres.2013.06.033

69. Irons TD, MacPhail RC, Hunter DL, Padilla S (2010) Acute neuroactive drug exposures alter locomotor activity in larval 
zebrafish. Neurotoxicol Teratol 32:84-90. https://doi.org/10. 1016/j.ntt.2009.04.066

70. Lautar SL, Rojas C, Slusher BS, Wozniak KM, Wu Y, Thomas AG, Waldon D, Li W et al (2005) DPP IV inhibitor blocks mescaline-induced scratching and amphetamine-induced hyperactivity in mice. Brain Res 1048:177-184. https://doi.org/10.1016/j. brainres.2005.04.069

71. Alttoa A, Eller M, Herm L, Rinken A, Harro J (2007) Amphetamine-induced locomotion, behavioral sensitization to amphetamine, and striatal D2 receptor function in rats with high or low spontaneous exploratory activity: Differences in the role of locus coeruleus. Brain Res 1131:138-148. https://doi.org/10. 1016/j.brainres.2006.10.075

72. Gormley S, Rompré P-P (2011) Blockade of mGLUR5 receptors differentially alters amphetamine-induced enhancement of locomotor activity and of brain stimulation reward. J Psychopharmacol 25:393-401. https://doi.org/10.1177/ 0269881110367460

73. Saylor AJ, McGinty JF (2008) Amphetamine-induced locomotion and gene expression are altered in BDNF heterozygous mice. Genes Brain Behav 7:906-914. https://doi.org/10.1111/j.1601183X.2008.00430.x

74. Salahpour A, Ramsey AJ, Medvedev IO, Kile B, Sotnikova TD, Holmstrand E, Ghisi V, Nicholls PJ et al (2008) Increased amphetamine-induced hyperactivity and reward in mice overexpressing the dopamine transporter. Proc Natl Acad Sci 105:44054410. https://doi.org/10.1073/pnas.0707646105

75. Pletnikov MV, Ayhan Y, Nikolskaia O, Xu Y, Ovanesov MV, Huang H, Mori S, Moran TH et al (2008) Inducible expression of mutant human DISC1 in mice is associated with brain and behavioral abnormalities reminiscent of schizophrenia. Mol Psychiatry 13:173-186. https://doi.org/10.1038/sj.mp.4002079

76. Karl T, Duffy L, Scimone A, Harvey RP, Schofield PR (2007) Altered motor activity, exploration and anxiety in heterozygous neuregulin 1 mutant mice: Implications for understanding schizophrenia. Genes Brain Behav 6:677-687. https://doi.org/10.1111/j. 1601-183X.2006.00298.X

77. Thyme SB, Pieper LM, Li EH et al (2019) Phenotypic landscape of schizophrenia-associated genes defines candidates and their shared functions. Cell 177:478-491.e20. https://doi.org/10.1016/ j.cell.2019.01.048

78. Wolman MA, Jain RA, Liss L, Granato M (2011) Chemical modulation of memory formation in larval zebrafish. Proc Natl Acad Sci 108:15468-15473. https://doi.org/10.1073/pnas.1107156108

79. Randlett O, Haesemeyer M, Forkin G et al (2019) Distributed plasticity drives visual habituation learning in larval Zebrafish. Curr Biol 29:1337-1345.e4. https://doi.org/10.1016/j.cub.2019. 02.039

80. Braff DL (1992) Gating and habituation of the startle reflex in schizophrenic patients. Arch Gen Psychiatry 49:206-215. https:// doi.org/10.1001/archpsyc.1992.01820030038005

81. Avery SN, McHugo M, Armstrong K, Blackford JU, Woodward ND, Heckers S (2019) Disrupted habituation in the early stage of psychosis. Biological Psychiatry: Cognitive Neuroscience and Neuroimaging 4:1004-1012. https://doi.org/10.1016/j.bpsc.2019. 06.007

82. Aggernaes B, Glenthoj BY, Ebdrup BH, Rasmussen H, Lublin H, Oranje B (2010) Sensorimotor gating and habituation in antipsychotic-naive, first-episode schizophrenia patients before and after 6 months' treatment with quetiapine. Int J Neuropsychopharmacol 13:1383-1395. https://doi.org/10.1017/S1461145710000787

83. Quednow BB, Frommann I, Berning J, Kühn KU, Maier W, Wagner M (2008) Impaired sensorimotor gating of the acoustic startle response in the prodrome of schizophrenia. Biol Psychiatry 64:766-773. https://doi.org/10.1016/j.biopsych.2008.04.019
84. Quednow BB, Wagner M, Westheide J, Beckmann K, Bliesener N, Maier W, Kühn KU (2006) Sensorimotor gating and habituation of the startle response in schizophrenic patients randomly treated with amisulpride or olanzapine. Biol Psychiatry 59:536545. https://doi.org/10.1016/j.biopsych.2005.07.012

85. Cadenhead KS, Swerdlow NR, Shafer KM, Diaz M, Braff DL (2000) Modulation of the startle response and startle laterality in relatives of schizophrenic patients and in subjects with schizotypal personality disorder: evidence of inhibitory deficits. Am J Psychiatry 157:1660-1668. https://doi.org/10.1176/appi.ajp.157. 10.1660

86. Duncan GE, Moy SS, Lieberman JA, Koller BH (2006) Effects of haloperidol, clozapine, and quetiapine on sensorimotor gating in a genetic model of reduced NMDA receptor function. Psychopharmacology 184:190-200. https://doi.org/10.1007/ s00213-005-0214-1

87. Kanahara N, Shimizu E, Ohgake S, Fujita Y, Kohno M, Hashimoto T, Matsuzawa D, Shirayama Y et al (2008) Glycine and d-serine, but not d-cycloserine, attenuate prepulse inhibition deficits induced by NMDA receptor antagonist MK-801. Psychopharmacology 198:363-374. https://doi.org/10.1007/ s00213-008-1151-6

88. Papaleo F, Yang F, Garcia S, Chen J, Lu B, Crawley JN, Weinberger DR (2012) Dysbindin-1 modulates prefrontal cortical activity and schizophrenia-like behaviors via dopamine/D2 pathways. Mol Psychiatry 17:85-98. https://doi.org/10.1038/mp. 2010.106

89. Baig SM, Koschak A, Lieb A, Gebhart M, Dafinger C, Nürnberg G, Ali A, Ahmad I et al (2011) Loss of Cav1.3 (CACNA1D) function in a human channelopathy with bradycardia and congenital deafness. Nat Neurosci 14:77-84. https://doi.org/10.1038/nn. 2694

90. Liaqat K, Raza SI, Lee K et al (2019) Identification of CACNA1D variants associated with sinoatrial node dysfunction and deafness in additional Pakistani families reveals a clinical significance. J Hum Genet 64:153-160. https://doi.org/10.1038/s10038-0180542-8

91. Giacomini NJ, Rose B, Kobayashi K, Guo S (2006) Antipsychotics produce locomotor impairment in larval zebrafish. Neurotoxicol Teratol 28:245-250. https://doi.org/10. 1016/j.ntt.2006.01.013

92. Idalencio R, Kalichak F, Rosa JGS, Oliveira TA, Koakoski G, Gusso D, Abreu MS, Giacomini ACV et al (2015) Waterborne Risperidone decreases stress response in zebrafish. PLoS One 10: e0140800. https://doi.org/10.1371/journal.pone.0140800

93. Magno LDP, Fontes A, Gonçalves BMN, Gouveia A (2015) Pharmacological study of the light/dark preference test in zebrafish (Danio rerio): waterborne administration. Pharmacol Biochem Behav 135:169-176. https://doi.org/10.1016/j.pbb. 2015.05.014

94. Bruni G, Rennekamp AJ, Velenich A, McCarroll M, Gendelev L, Fertsch E, Taylor J, Lakhani P et al (2016) Zebrafish behavioral profiling identifies multitarget antipsychotic-like compounds. Nat Chem Biol 12:559-566. https://doi.org/10.1038/nchembio.2097

95. Boehmler W, Carr T, Thisse C, Thisse B, Canfield VA, Levenson $R$ (2007) D4 dopamine receptor genes of zebrafish and effects of the antipsychotic clozapine on larval swimming behaviour. Genes Brain Behav 6:155-166. https://doi.org/10.1111/j.1601-183X. 2006.00243.x

96. Ghodke-Puranik Y, Thorn CF, Lamba JK, Leeder JS, Song W, Birnbaum AK, Altman RB, Klein TE (2013) Valproic acid pathway: pharmacokinetics and pharmacodynamics. Pharmacogenet Genomics 23:236-241. https://doi.org/10.1097/FPC. 0b013e32835ea0b2

97. Johannesen KM, Gardella E, Linnankivi T, Courage C, de Saint Martin A, Lehesjoki AE, Mignot C, Afenjar A et al (2018) 
Defining the phenotypic spectrum of SLC6A1 mutations. Epilepsia 59:389-402. https://doi.org/10.1111/epi.13986

98. Franceschetti S, Hamon B, Heinemann U (1986) The action of valproate on spontaneous epileptiform activity in the absence of synaptic transmission and on evoked changes in $[\mathrm{Ca} 2+] 0$ and $[\mathrm{K}+$ ]0 in the hippocampal slice. Brain Res 386:1-11. https://doi.org/ 10.1016/0006-8993(86)90135-6

99. Leysen JE, Janssen PMF, Schotte A, Luyten WHML, Megens AAHP (1993) Interaction of antipsychotic drugs with neurotransmitter receptor sites in vitro and in vivo in relation to pharmacological and clinical effects: role of $5 \mathrm{HT} 2$ receptors. Psychopharmacology 112:S40-S54. https://doi.org/10.1007/ BF02245006

100. Kalichak F, Idalencio R, da Rosa JGS, Barcellos HHA, Fagundes M, Piato A, Barcellos LJG (2017) Psychotropic in the environment: risperidone residues affect the behavior of fish larvae. Sci Rep 7:14121. https://doi.org/10.1038/s41598-017-14575-7

101. Uhlen M, Fagerberg L, Hallstrom BM, Lindskog C, Oksvold P, Mardinoglu A, Sivertsson A, Kampf C et al (2015) Tissue-based map of the human proteome. Science 347:1260419-1260419. https://doi.org/10.1126/science.1260419

102. Tissue expression of CACNA1D - Summary - The HUMAN PROTEIN ATLAS. https://www.proteinatlas.org/ ENSG00000157388-CACNA1D/tissue. Accessed 25 Jun 2020

103. Hetzenauer A, Sinnegger-Brauns MJ, Striessnig J, Singewald N (2006) Brain activation pattern induced by stimulation of L-type $\mathrm{Ca} 2+-$ channels: contribution of $\mathrm{CaV} 1.3$ and $\mathrm{CaV} 1.2$ isoforms. Neuroscience 139:1005-1015. https://doi.org/10.1016/j. neuroscience.2006.01.059

104. Gene Detail: Allen brain atlas: mouse brain. http://mouse.brainmap.org/gene/show/12074. Accessed 25 Jun 2020

105. Lein ES, Hawrylycz MJ, Ao N, Ayres M, Bensinger A, Bernard A, Boe AF, Boguski MS et al (2007) Genome-wide atlas of gene expression in the adult mouse brain. Nature 445:168-176. https:// doi.org/10.1038/nature05453
106. Gawel K, Banono NS, Michalak A, Esguerra CV (2019) A critical review of zebrafish schizophrenia models: time for validation? Neurosci Biobehav Rev 107:6-22. https://doi.org/10.1016/j. neubiorev.2019.08.001

107. Gawel K, Langlois M, Martins T, van der Ent W, Tiraboschi E, Jacmin M, Crawford AD, Esguerra CV (2020) Seizing the moment: zebrafish epilepsy models. Neurosci Biobehav Rev 116:120. https://doi.org/10.1016/j.neubiorev.2020.06.010

108. Eimon PM, Ghannad-Rezaie M, De Rienzo G et al (2018) Brain activity patterns in high-throughput electrophysiology screen predict both drug efficacies and side effects. Nat Commun 9:219. https://doi.org/10.1038/s41467-017-02404-4

109. Suster ML, Abe G, Schouw A, Kawakami K (2011) Transposonmediated BAC transgenesis in zebrafish. Nat Protoc 6:1998-2021. https://doi.org/10.1038/nprot.2011.416

110. Kawakami K (2005) Transposon tools and methods in zebrafish. Dev Dyn 234:244-254. https://doi.org/10.1002/dvdy.20516

111. Hwang WY, Fu Y, Reyon D, Gonzales APW, Joung JK, Yeh JRJ (2015) Targeted mutagenesis in zebrafish using CRISPR RNAguided nucleases. In: Lundgren M, Charpentier E, Fineran PC (eds) CRISPR. Springer New York, New York, NY, pp. 317-334

112. Arranz MJ, Rivera M, Munro JC (2011) Pharmacogenetics of response to antipsychotics in patients with schizophrenia. CNS Drugs 25:933-969. https://doi.org/10.2165/11595380000000000-00000

113. Vita A, Minelli A, Barlati S, Deste G, Giacopuzzi E, Valsecchi P, Turrina C, Gennarelli M (2019) Treatment-resistant schizophrenia: genetic and neuroimaging correlates. Front Pharmacol 10: 402. https://doi.org/10.3389/fphar.2019.00402

Publisher's Note Springer Nature remains neutral with regard to jurisdictional claims in published maps and institutional affiliations. 